\title{
Modeling and Optimization of Cutting Parameters during Machining of Austenitic Stainless Steel AISI304 Using RSM and Desirability Approach
}

\author{
Septi Boucherit ${ }^{\star}$, Sofiane Berkani1, Mohamed Athmane Yallese', Riad Khettabi', Tarek Mabrouki² \\ ${ }^{1}$ Mechanics and Structures Research Laboratory (LMS), Université 8 Mai 1945 Guelma, P. O. B. 401, 24000 Guelma, Algeria \\ 2 Applied Mechanics and Engineering Laboratory (LR-11-ES19), University of Tunis El Manar, ENIT, P. O. B. 37, Le Belvédère, \\ 1002 Tunis, Tunisia \\ * Corresponding author, e-mail: boucherit.sebti@univ-guelma.dz
}

Received: 17 March 2018, Accepted: 20 November 2020, Published online: 21 December 2020

\begin{abstract}
In the current paper, cutting parameters during turning of AISI 304 Austenitic Stainless Steel are studied and optimized using Response Surface Methodology (RSM) and the desirability approach. The cutting tool inserts used in this work were the CVD coated carbide. The cutting speed $(v c)$, the feed rate $(f)$ and the depth of cut $(a p)$ were the main machining parameters considered in this study. The effects of these parameters on the surface roughness $(R a)$, cutting force $(F c)$, the specific cutting force $(K c)$, cutting power $(P c)$ and the Material Removal Rate (MRR) were analyzed by ANOVA analysis.

The results showed that $f$ is the most important parameter that influences $R a$ with a contribution of $89.69 \%$, while ap was identified as the most significant parameter (46.46 \%) influence the $F c$ followed by $f(39.04 \%)$. Kc is more influenced by $f(38.47 \%)$ followed by ap (16.43\%) and Vc (7.89\%). However, Pc is more influenced by $V c$ (39.32 \%) followed by ap (27.50 \%) and $f(23.18 \%)$.

The Quadratic mathematical models, obtained by the RSM, presenting the evolution of $R a, F c, K c$ and $P c$ based on ( $v c, f$, and $a p$ ) were presented. A comparison between experimental and predicted values presents good agreements with the models found.

Optimization of the machining parameters to achieve the maximum MRR and better Ra was carried out by a desirability function. The results showed that the optimal parameters for maximal MRR and best $R a$ were found as $(v c=350 \mathrm{~m} / \mathrm{min}, f=0.088 \mathrm{~mm} / \mathrm{rev}$, and $a p=0.9 \mathrm{~mm})$.
\end{abstract}

\section{Keywords}

machinability, austenitic stainless steel, CVD coated carbide tool, ANOVA, RSM, desirability approach

\section{Introduction}

The AISI 304 austenitic stainless steel is an alloy having strategic qualities such as good corrosion resistance, a good formability and non-magnetic properties. All these properties qualify this type of steel as a good choice for many applications in various engineering field (chemical equipment, food processing, pressure vessels, cryogenic tanks and paper industry). However, machining this type of steel is more difficult compared to other steel due to high tensile strength, high ductility, high work hardening rate, low thermal conductivity and high tendency of the Built-Up Edge (BUE) formation.

Various studies have been carried out in order to optimize the machinability of this type of material. Using $\mathrm{L}_{27}$ orthogonal array Taguchi design, Nayak et al. [1] studied the influence of cutting parameters on Material Removal
Rate, cutting force and surface roughness during dry machining of AISI 304 austenitic stainless steel. The grey relation analysis was used to optimize the cutting parameters in turning operation. A confirmatory test was done to support the findings and an improvement of $88.78 \%$ in grey relation was observed. The optimization of dry turning parameters of two different grades of nitrogen alloyed duplex stainless steel by using Taguchi method, has been presented by Selvaraj et al. [2] and they find that the feed rate is the more significant parameter influencing the surface roughness and cutting force. The cutting speed was identified as the more significant parameter influencing the tool wear. Moreover, the lubricating mode can have significant influence on the cutting performance indicators. Xavior and Adithan [3] have studied the influence of 
coconut oil on tool wear and surface roughness during turning of AISI 304 with carbide tool. They showed that the coconut oil performed better than the other cutting fluids in reducing the tool wear with improving the surface finish.

The optimization of cutting speed and feed rate in order to obtain favorable performance characteristics has also been reported recently by numerous researches (Kalidass et al. [4], Kaladhar et al. [5], Kulkarni et al. [6]). A review of the Machining of hardened steel has been carried out by Chinchanikar and Choudhury [7]. It has been found that the analysis of most of the studies evaluating machining performance in terms of the tool life, surface roughness, cutting forces and chip morphology during machining of hardened steel at different levels of hardness using coated carbide tools have shown that the optimal combination of low feed rate and low depth of cut with higher cutting speed is beneficial. Experimental investigations indicate that the cutting force components were influenced principally by depth of cut and work piece hardness; however, both feed rate and work piece hardness had statistical significance on surface roughness. Selvaraj and Chandramohan [8] examined surface roughness during machining of AISI 304 ASS in dry turning operation using $\mathrm{TiC}$ and $\mathrm{TiCN}$ coated tungsten carbide cutting tool. It was noted that feed rate was the most important factor that affect the surface roughness, followed by the cutting speed and the depth of cut. Krolczyk et al. [9] in their studies on dry turning of Duplex stainless steel with coated carbide tools have shown using RSM method that the feed rate is the main factor influencing the surface roughness.

The effects of the cutting parameters (spindle speed, feed rate and axial depth of cut) on surface roughness during end milling of duplex stainless steel have been studied using Response Surface Methodology by Philip et al. [10]. They found according to the prediction equation that the feed rate was the most important factor that influences the surface roughness followed by axial depth of cut and spindle speed. In the goal to minimize the surface roughness during the dry turning of AISI 304 Stainless Steel, Waychal and Kulkarni [11] found that the optimal process parameters considered as the main influencing factors on the surface roughness were the depth of cut and cutting speed. Subsequently, the better surface finish was found at lower feed rates and high cutting speed. Kumar et al. [12] investigated the machining performance indicators (tool wear, surface roughness, cutting zone temperature and force) during hard turning of super duplex stainless steel using uncoated carbide tool. Experimental results showed that the feed rate is the most dominating factor that influences the surface roughness, cutting zone temperature and the force acted along " $x$ " axis. However, the tool wear was highly influenced by the depth of cut.

From the literature review, it can be concluded that the literature is very rich in the field of machining of austenitic stainless steel. However, the results of all the works carried out by the experimental design (DOE) method remain valid only for the same tool-material pair and the same range of variation of the selected cutting parameters (i.e. $v c, f$ and $a p$ ).

In the current work, a model based on Response Surface Methodology was used to establish the relationships between the three cutting parameters $(v c, f, a p)$ and cutting performance which is characterized by surface roughness, cutting force, specific cutting force and cutting power during turning of AISI 304 Austenitic Stainless Steel. Results were analyzed and optimized using the desirability approach. A complementary confirmation test was carried out to evaluate the predicted models.

\section{Experimental procedure}

\subsection{Experimental setup}

The experiment was performed by using the lathe "TOS TRENCIN; model SN40C". This lathe is characterized by $6.6 \mathrm{~kW}$ spindle power and a maximum spindle speed of $2000 \mathrm{rpm}$. The cutting insert used is SANDVIK "Ti(C,N)/ A12O3/TiN" CVD multilayer coated carbide referenced as GC2015 (SNMG 12-0408-MF). The cutting inserts were clamped on a right- hand tool holder with designation PSBNR25x25M12.

The workpiece adopted in the current study was AISI 304 Austenitic stainless steel with chemical composition $(0.02 \% \mathrm{C}, 16.91 \% \mathrm{Cr}, 7.69 \% \mathrm{Ni}, 0.33 \% \mathrm{Si}$, $1.44 \% \mathrm{Mn}, 0.41 \% \mathrm{Mo}, 72.10 \% \mathrm{Fe}$ and $1.1 \%$ other components). The dimensions are $100 \mathrm{~mm}$ for diameter and $350 \mathrm{~mm}$ for length.

The mechanical and physical properties of the workpiece are summarized in the Table 1 .

Three different components of forces, commonly called, cutting force $(F c)$, feed force $(F a)$ and thrust force $(F r)$ were measured through the Kistler piezoelectric dynamometer (model 9121) (Fig. 1).

Table 1 Physical and mechanical properties of AISI 304

\begin{tabular}{lcccc}
\hline $\begin{array}{l}\text { Modulus of } \\
\text { elasticity } \\
\text { at } 20{ }^{\circ} \mathrm{C}, E\end{array}$ & $\begin{array}{c}\text { Thermal } \\
\text { conductivity }\end{array}$ & $\begin{array}{c}\text { coefficient } \\
\text { dilatation } \\
\text { at } 100{ }^{\circ} \mathrm{C}, \alpha\end{array}$ & $\begin{array}{c}\text { Elongation } \\
\text { at break }\end{array}$ & $\begin{array}{c}\text { Hardness, } \\
\text { Vickers }\end{array}$ \\
\hline$[\mathrm{GPa}]$ & {$\left[\mathrm{W} \mathrm{m}^{-1} \mathrm{~K}^{-1}\right]$} & {$\left[10-6{ }^{\circ} \mathrm{C}^{-1}\right]$} & {$[\%]$} & {$[\mathrm{HV}]$} \\
200 & 15 & 16 & 45 & $160-200$ \\
\hline
\end{tabular}


workpiece and the cutting insert

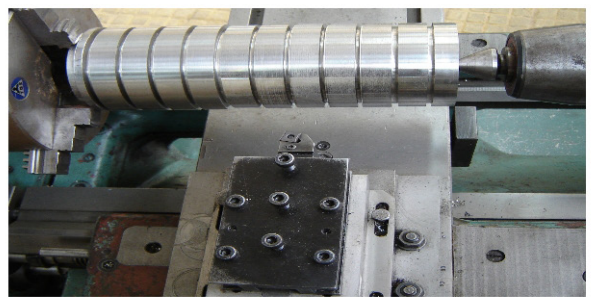

Surftest 201 Mitutoyo
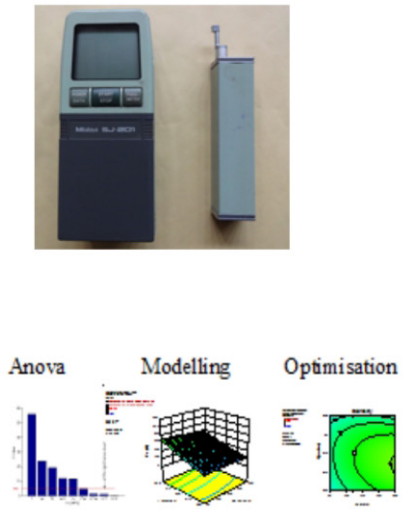

Fig. 1 Schematic diagram of experimental arrangement

The values were monitored continuously and recorded through a threechannel charge amplifier (model 5019) with data acquisition system (Fig. 1). A roughness meter (2d) Surftest 201 Mitutoyo was used to measure surface roughness $R a$, according to the examination length of $4 \mathrm{~mm}$ with a cutoff of $0.8 \mathrm{~mm}$ and the measured range of $0.05-$ $40 \mu \mathrm{m}$. The roughness measurements were obtained without disassembling the workpiece in order to reduce uncertainties that can be caused by the resumption operations.

A noncontact threedimensional white light interferometer, Altisurf 500, with a sensor having a dynamic range of $50 \mathrm{~nm}-300 \mu \mathrm{m}$, was employed to measure and investigate the surface topography.

The other aspects of machinability such as specific cutting force $(K c)$ and cutting power $(P c)$ are calculated regarding the obtained cutting force by using the Eqs. (1) and (2). The Material Removal Rate (MRR) can be, also, calculated using the Eq. (3).

$$
\begin{aligned}
& K c=\frac{F c}{S}=\frac{F c}{f \times a p} \\
& P c=\frac{F c \times V c}{60}
\end{aligned}
$$

$\mathrm{MRR}=V c \times f \times a p$
Where $K c$ is the specific cutting force $\left(\mathrm{N} / \mathrm{mm}^{2}\right), F c$ is the cutting force $(\mathrm{N})$, and $S$ is the shear plane area $\left(\mathrm{mm}^{2}\right), P c$ is cutting power (W) and MRR is Material Removal Rate $\left(\mathrm{cm}^{3} / \mathrm{min}\right), f$ is feed rate, ap is depth of cut, $v c$ is cutting speed.

\subsection{Response Surface Methodology}

The Response Surface Methodology (RSM) is a dynamic and foremost important tool of Design of Experiment (DOE). RSM was successfully applied for prediction and optimization of cutting parameters by Mukherjee and Raj [13] and Benardos and Vosniakos [14]. In this study the RSM was used in order to obtain the machinability performances of surface roughness, cutting force, specific cutting force and cutting power. The three principal machining parameters considered in this work were the cutting speed $(v c)$, the feed rate $(f)$ and the depth of cut (ap).

The relationship between the three independent input variables cited below, and the output $\varphi$ is given by Eq. (4):

$\varphi=f(v c, f, a p)+e_{i j}$,

where $\varphi$ is the desired response and $f$ is response surface. In the procedure of analysis, the approximation of $\varphi$ was proposed using the fitted second-order polynomial regression model which is called the quadratic model. The quadratic model of $\varphi$ can be written as follows:

$\varphi=a_{0}+\sum_{i=1}^{k} a_{i} X_{i}+\sum_{i=1}^{k} a_{i i} X_{i}^{2}+\sum_{i \neq j}^{k} a_{i j} X_{i} X_{j}$,

where $a_{0}$ is constant, $a_{i}, a_{i i}$, and $a_{i j}$ represent the coefficients of linear, quadratic and cross product terms, respectively. $X_{i}$ represents the level attributed to the factor $i$.

\subsection{Design of Experiment}

In order to develop the mathematical model based on RSM, the $\mathrm{L}_{27}\left(3^{13}\right)$ Taguchi standard orthogonal array is adopted as the experimental design method. This plan has 27 rows and 13 columns [15] as shown in Table 2. The first column was assigned to the cutting speed $(v c)$, the second column to the feed rate $(f)$, the fifth column to the depth of cut ( $a p)$, and the remaining columns to the interactions. One test was performed for each combination resulting in a total of 27 runs.

Three levels are defined for each factor and the ranges of the selected factors were based on the preliminary tests. The factors and their levels in the present investigation are presented in Table 3.

The experimental parameters used and the corresponding responses are given in Table 4. The first column of the Table 4 is assigned to cutting speed $(v c)$, the second to 
Table 2 Orthogonal array $\mathrm{L}_{27}\left(3^{13}\right)$ of Taguchi

\begin{tabular}{|c|c|c|c|c|c|c|c|c|c|c|c|c|c|}
\hline $\mathrm{L}_{27}\left(3^{13}\right)$ & 1 & 2 & 3 & 4 & 5 & 6 & 7 & 8 & 9 & 10 & 11 & 12 & 13 \\
\hline 1 & 1 & 1 & 1 & 1 & 1 & 1 & 1 & 1 & 1 & 1 & 1 & 1 & 1 \\
\hline 2 & 1 & 1 & 1 & 1 & 2 & 2 & 2 & 2 & 2 & 2 & 2 & 2 & 2 \\
\hline 3 & 1 & 1 & 1 & 1 & 3 & 3 & 3 & 3 & 3 & 3 & 3 & 3 & 3 \\
\hline 4 & 1 & 2 & 2 & 2 & 1 & 1 & 1 & 2 & 2 & 2 & 3 & 3 & 3 \\
\hline 5 & 1 & 2 & 2 & 2 & 2 & 2 & 2 & 3 & 3 & 3 & 1 & 1 & 1 \\
\hline 6 & 1 & 2 & 2 & 2 & 3 & 3 & 3 & 1 & 1 & 1 & 2 & 2 & 2 \\
\hline 7 & 1 & 3 & 3 & 3 & 1 & 1 & 1 & 3 & 3 & 3 & 2 & 2 & 2 \\
\hline 8 & 1 & 3 & 3 & 3 & 2 & 2 & 2 & 1 & 1 & 1 & 3 & 3 & 3 \\
\hline 9 & 1 & 3 & 3 & 3 & 3 & 3 & 3 & 2 & 2 & 2 & 1 & 1 & 1 \\
\hline 10 & 2 & 1 & 2 & 3 & 1 & 2 & 3 & 1 & 2 & 3 & 1 & 2 & 3 \\
\hline 11 & 2 & 1 & 2 & 3 & 2 & 3 & 1 & 2 & 3 & 1 & 2 & 3 & 1 \\
\hline 12 & 2 & 1 & 2 & 3 & 3 & 1 & 2 & 3 & 1 & 2 & 3 & 1 & 2 \\
\hline 13 & 2 & 2 & 3 & 1 & 1 & 2 & 3 & 2 & 3 & 1 & 3 & 1 & 2 \\
\hline 14 & 2 & 2 & 3 & 1 & 2 & 3 & 1 & 3 & 1 & 2 & 1 & 2 & 3 \\
\hline 15 & 2 & 2 & 3 & 1 & 3 & 1 & 2 & 1 & 2 & 3 & 2 & 3 & 1 \\
\hline 16 & 2 & 3 & 1 & 2 & 1 & 2 & 3 & 3 & 1 & 2 & 2 & 3 & 1 \\
\hline 17 & 2 & 3 & 1 & 2 & 2 & 3 & 1 & 1 & 2 & 3 & 3 & 1 & 2 \\
\hline 18 & 2 & 3 & 1 & 2 & 3 & 1 & 2 & 2 & 3 & 1 & 1 & 2 & 3 \\
\hline 19 & 3 & 1 & 3 & 2 & 1 & 3 & 2 & 1 & 3 & 2 & 1 & 3 & 2 \\
\hline 20 & 3 & 1 & 3 & 2 & 2 & 1 & 3 & 2 & 1 & 3 & 2 & 1 & 3 \\
\hline 21 & 3 & 1 & 3 & 2 & 3 & 2 & 1 & 3 & 2 & 1 & 3 & 2 & 1 \\
\hline 22 & 3 & 2 & 1 & 3 & 1 & 3 & 2 & 2 & 1 & 3 & 3 & 2 & 1 \\
\hline 23 & 3 & 2 & 1 & 3 & 2 & 1 & 3 & 3 & 2 & 1 & 1 & 3 & 2 \\
\hline 24 & 3 & 2 & 1 & 3 & 3 & 2 & 1 & 1 & 3 & 2 & 2 & 1 & 3 \\
\hline 25 & 3 & 3 & 2 & 1 & 1 & 3 & 2 & 3 & 2 & 1 & 2 & 1 & 3 \\
\hline 26 & 3 & 3 & 2 & 1 & 2 & 1 & 3 & 1 & 3 & 2 & 3 & 2 & 1 \\
\hline 27 & 3 & 3 & 2 & 1 & 3 & 2 & 1 & 2 & 1 & 3 & 1 & 3 & 2 \\
\hline
\end{tabular}

Table 3 Factors levels array

\begin{tabular}{lccccc}
\hline $\begin{array}{l}\text { Control } \\
\text { parameters }\end{array}$ & Unit & Symbol & \multicolumn{3}{c}{ Levels } \\
\hline Cutting speed & $\mathrm{m} / \mathrm{min}$ & $V c$ & 90 & 180 & 350 \\
Feed rate & $\mathrm{mm} / \mathrm{rev}$ & $f$ & 0.08 & 0.16 & 0.24 \\
Depth of cut & $\mathrm{mm}$ & $a p$ & 0.30 & 0.60 & 0.90 \\
\hline
\end{tabular}

feed rate $(f)$, the third to depth of cut (ap). The measurement results of the surface roughness $(R a)$ and of the cutting force $(F c)$ are given in the fourth and fifth columns the sixth and seventh columns are assigned to specific cutting force $(K c)$ and cutting power $(P c)$, at last the column eight is assigned to Material Removal Rate (MRR).

\section{Results and discussion}

The effect of cutting conditions on surface roughness, cutting force, specific cutting force, power and Material Removal Rate obtained from the turning of austenitic AISI 304 stainless steel presented in the Table 4 is discussed in three different parts such as the variance analysis, the regression equation for various responses and the responses surface analysis. The obtained results were analyzed using the Design-expert 9, statistical analysis software which is widely exploited in many engineering optimizations.

\subsection{Analyze of variance}

Tables 5-8 show the results of analysis of variance for surface roughness, tangential force, specific cutting force and cutting power. In addition the same Tables 5-8 show the Degrees of Freedom (DF), Sum of Square (SS), Mean of Square (MS), $F$-value and $P$-value. The ration of contribution of different factors (Cont.\%) and their interactions were also presented. The purpose is to analyze the influence of cutting parameters $(v c, f$ and $a p)$ on the different cutting phenomena $(R a, F c, K c$, and $P c$ ). The $P$-value is a statistical index used in the analysis of variance. In the statistical significance, the lower $P$-value means that the tested parameter is more significant. Often the analyzed parameter is considered as significant when the $P$-value is less than 0.05 . In this study, the significance of all cutting parameters was proved while the $P$-values of all parameters were less than 0.05 . Therefore, it seems to be important to study the effects of each cutting condition on the machining characteristics.

It can be observed from ANOVA results for $R a$ presented in Table 5 that the feed rate is the most important factor affecting $R a$; similar results were reported by Berkani et al. [16] and Bouzid et al. [17]. Its contribution is $89.69 \%$ followed by the interaction $f^{2}$ with a contribution of $3.02 \%$. The cutting speed and the depth of cut were not significant because the contribution recorded was respectively $(0.41 \%$ and $0.02 \%)$.

However, the influence of cutting conditions on cutting force shows that the cutting speed has a small effect compared with that of the feed rate and the depth of cut and this can be noted in ANOVA analysis presented in Table 6. The depth of cut has a contribution ratio of $46.46 \%$ and $39.04 \%$ for the feed rate, but the cutting speed presents only a $1.52 \%$.

The ANOVA results of the specific cutting force and the cutting power are presented respectively in the Tables 7 and 8. It is clear from the results of ANOVA shown in Table 7 that the feed rate affects significantly specific cutting force and its contribution is $38.47 \%$. The second parameter influencing specific cutting force is depth of cut and its contribution is $16.43 \%$. Hence; the influence of cutting speed is less important and its contribution is 
Table 4 Orthogonal array for responses

\begin{tabular}{|c|c|c|c|c|c|c|c|c|}
\hline \multirow[b]{2}{*}{$\mathrm{N}^{\circ}$ Test } & \multicolumn{3}{|c|}{ Process parameter settings } & \multicolumn{5}{|c|}{ Machinability characteristics } \\
\hline & $\begin{array}{c}v c \\
{[\mathrm{~m} / \mathrm{min}]}\end{array}$ & $\begin{array}{c}f \\
{[\mathrm{~mm} / \mathrm{rev}]}\end{array}$ & $\begin{array}{c}a p \\
{[\mathrm{~mm}]}\end{array}$ & $\begin{array}{c}R a \\
{[\mu \mathrm{m}]}\end{array}$ & $\begin{array}{l}F c \\
{[\mathrm{~N}]}\end{array}$ & $\begin{array}{c}K c \\
{[\mathrm{MPa}]}\end{array}$ & $\begin{array}{c}P c \\
{[\mathrm{~W}]}\end{array}$ & $\begin{array}{c}\text { MRR } \\
{\left[\mathrm{cm}^{3} / \mathrm{min}\right]}\end{array}$ \\
\hline 1 & 90 & 0.08 & 0.3 & 0.82 & 92.31 & 3846.25 & 138.47 & 2.16 \\
\hline 2 & 90 & 0.08 & 0.6 & 0.62 & 131.56 & 2740.83 & 197.34 & 4.32 \\
\hline 3 & 90 & 0.08 & 0.9 & 0.79 & 208.50 & 2895.83 & 312.75 & 6.48 \\
\hline 4 & 90 & 0.16 & 0.3 & 1.60 & 130.60 & 2720.83 & 195.90 & 4.32 \\
\hline 5 & 90 & 0.16 & 0.6 & 1.99 & 214.00 & 2229.17 & 321.00 & 8.64 \\
\hline 6 & 90 & 0.16 & 0.9 & 1.28 & 366.49 & 2545.07 & 549.74 & 12.96 \\
\hline 7 & 90 & 0.24 & 0.3 & 3.63 & 195.69 & 2717.92 & 293.54 & 6.48 \\
\hline 8 & 90 & 0.24 & 0.6 & 3.13 & 330.22 & 2293.19 & 495.33 & 12.96 \\
\hline 9 & 90 & 0.24 & 0.9 & 2.39 & 538.58 & 2493.43 & 807.87 & 19.44 \\
\hline 10 & 180 & 0.08 & 0.3 & 0.66 & 74.50 & 3104.17 & 223.50 & 5.28 \\
\hline 11 & 180 & 0.08 & 0.6 & 1.00 & 147.89 & 3081.04 & 443.67 & 10.56 \\
\hline 12 & 180 & 0.08 & 0.9 & 0.55 & 217.04 & 3014.44 & 651.12 & 15.84 \\
\hline 13 & 180 & 0.16 & 0.3 & 1.24 & 128.37 & 2674.38 & 385.11 & 10.56 \\
\hline 14 & 180 & 0.16 & 0.6 & 1.84 & 217.31 & 2263.65 & 651.93 & 21.12 \\
\hline 15 & 180 & 0.16 & 0.9 & 1.61 & 325.18 & 2258.19 & 975.54 & 31.68 \\
\hline 16 & 180 & 0.24 & 0.3 & 3.32 & 190.84 & 2650.56 & 572.52 & 15.84 \\
\hline 17 & 180 & 0.24 & 0.6 & 3.19 & 346.24 & 2404.44 & 1038.72 & 31.68 \\
\hline 18 & 180 & 0.24 & 0.9 & 3.36 & 497.38 & 2302.69 & 1492.14 & 47.52 \\
\hline 19 & 350 & 0.08 & 0.3 & 0.51 & 90.35 & 3764.58 & 527.04 & 8.4 \\
\hline 20 & 350 & 0.08 & 0.6 & 0.53 & 127.91 & 2664.79 & 746.14 & 16.8 \\
\hline 21 & 350 & 0.08 & 0.9 & 1.36 & 177.13 & 2460.14 & 1033.26 & 25.2 \\
\hline 22 & 350 & 0.16 & 0.3 & 1.81 & 120.68 & 2514.17 & 703.97 & 16.8 \\
\hline 23 & 350 & 0.16 & 0.6 & 1.59 & 170.30 & 1773.96 & 993.42 & 33.6 \\
\hline 24 & 350 & 0.16 & 0.9 & 1.58 & 300.32 & 2085.56 & 1751.87 & 50.4 \\
\hline 25 & 350 & 0.24 & 0.3 & 3.60 & 159.04 & 2208.89 & 927.73 & 25.2 \\
\hline 26 & 350 & 0.24 & 0.6 & 3.19 & 300.03 & 2083.54 & 1750.18 & 50.4 \\
\hline 27 & 350 & 0.24 & 0.9 & 3.58 & 429.37 & 1987.82 & 2504.66 & 75.6 \\
\hline
\end{tabular}

Table 5 ANOVA table for $R a$

\begin{tabular}{|c|c|c|c|c|c|c|c|}
\hline Source & SS & $\mathrm{DF}$ & MS & $F$-value & $P$-value & Cont.\% & Remark \\
\hline Model & 30.08 & 9 & 3.34 & 41.66 & $<0.0001$ & & Significant \\
\hline$v c$ & 0.13 & 1 & 0.13 & 1.56 & 0.2288 & 0.41 & Insignificant \\
\hline$f$ & 28.20 & 1 & 28.20 & 351.48 & $<0.0001$ & 89.69 & Significant \\
\hline$a p$ & $8.225 \mathrm{E}-003$ & 1 & $8.225 \mathrm{E}-003$ & 0.10 & 0.7527 & 0.02 & Insignificant \\
\hline$v c \times f$ & 0.082 & 1 & 0.082 & 1.02 & 0.3269 & 0.26 & Insignificant \\
\hline$v c \times a p$ & 0.33 & 1 & 0.33 & 4.14 & 0.0579 & 1.04 & Insignificant \\
\hline$f \times a p$ & 0.31 & 1 & 0.31 & 3.87 & 0.0657 & 0.98 & Insignificant \\
\hline$v c^{2}$ & 4.249E008 & 1 & 4.249E008 & $5.297 \mathrm{E} 007$ & 0.9994 & 0.00 & Insignificant \\
\hline$f^{2}$ & 0.95 & 1 & 0.95 & 11.80 & 0.0032 & 3.02 & Significant \\
\hline$a p^{2}$ & 4.091E003 & 1 & 4.091E003 & 0.051 & 0.8240 & 0.01 & Insignificant \\
\hline Error & 1.36 & 17 & 0.080 & & & & \\
\hline Total & 31.44 & 26 & & & & 100 & \\
\hline
\end{tabular}


Table 6 ANOVA table for $F_{C}$

\begin{tabular}{|c|c|c|c|c|c|c|c|}
\hline Source & SS & DF & MS & $F$-value & $P$-value & Cont. $\%$ & Remark \\
\hline Model & $4.017 \mathrm{E}+005$ & 9 & 44632.68 & 285.46 & $<0.0001$ & & Significant \\
\hline$v c$ & 6153.84 & 1 & 6153.84 & 39.36 & $<0.0001$ & 1.52 & Significant \\
\hline$f$ & $1.579 \mathrm{E}+005$ & 1 & $1.579 \mathrm{E}+005$ & 1009.57 & $<0.0001$ & 39.04 & Significant \\
\hline ap & $1.879 \mathrm{E}+005$ & 1 & $1.879 \mathrm{E}+005$ & 1201.76 & $<0.0001$ & 46.46 & Significant \\
\hline$v c \times f$ & 1715.52 & 1 & 1715.52 & 10.97 & 0.0041 & 0.42 & Significant \\
\hline$v c \times a p$ & 2182.85 & 1 & 2182.85 & 13.96 & 0.0016 & 0.54 & Significant \\
\hline$f \times a p$ & 27480.26 & 1 & 27480.26 & 175.75 & $<0.0001$ & 6.79 & Significant \\
\hline$v c^{2}$ & 194.22 & 1 & 194.22 & 1.24 & 0.2806 & 0.04 & Insignificant \\
\hline$f^{2}$ & 1757.65 & 1 & 1757.65 & 11.24 & 0.0038 & 0.43 & Significant \\
\hline$a p^{2}$ & 1364.54 & 1 & 1364.54 & 8.73 & 0.0089 & 0.33 & Significant \\
\hline Error & 2658.04 & 17 & 156.36 & & & & \\
\hline Total & $4.044 \mathrm{E}+005$ & 26 & & & & 100 & \\
\hline
\end{tabular}

Table 7 ANOVA table for $K c$

\begin{tabular}{|c|c|c|c|c|c|c|c|}
\hline Source & SS & DF & MS & $F$-value & $P$-value & Cont. $\%$ & Remark \\
\hline Model & $5.367 \mathrm{E}+006$ & 9 & $5.964 \mathrm{E}+005$ & 14.24 & $<0.0001$ & & Significant \\
\hline$v c$ & $4.799 \mathrm{E}+005$ & 1 & $4.799 \mathrm{E}+005$ & 11.46 & 0.0035 & 7.89 & Significant \\
\hline$f$ & $2.339 \mathrm{E}+006$ & 1 & $2.339 \mathrm{E}+006$ & 55.83 & $<0.0001$ & 38.47 & Significant \\
\hline$a p$ & $9.991 \mathrm{E}+005$ & 1 & $9.991 \mathrm{E}+005$ & 23.85 & 0.0001 & 16.43 & Significant \\
\hline$v c \times f$ & 42295.68 & 1 & 42295.68 & 1.01 & 0.3290 & 0.69 & Insignificant \\
\hline$v c \times a p$ & 47557.32 & 1 & 47557.32 & 1.14 & 0.3015 & 0.78 & Insignificant \\
\hline$f \times a p$ & $2.005 \mathrm{E}+005$ & 1 & $2.005 \mathrm{E}+005$ & 4.79 & 0.0429 & 3.29 & Significant \\
\hline$v c^{2}$ & 5973.02 & 1 & 5973.02 & 0.14 & 0.7104 & 0.09 & Insignificant \\
\hline$f^{2}$ & $8.029 \mathrm{E}+005$ & 1 & $8.029 \mathrm{E}+005$ & 19.17 & 0.0004 & 13.20 & Significant \\
\hline$a p^{2}$ & $4.961 \mathrm{E}+005$ & 1 & $4.961 \mathrm{E}+005$ & 11.84 & 0.0031 & 8.16 & Significant \\
\hline Error & $7.121 \mathrm{E}+005$ & 17 & 41885.79 & & & & \\
\hline Total & $6.079 \mathrm{E}+006$ & 26 & & & & 100 & \\
\hline
\end{tabular}

Table 8 ANOVA table for $P c$

\begin{tabular}{|c|c|c|c|c|c|c|c|}
\hline Source & SS & DF & MS & $F$-value & $P$-value & Cont. $\%$ & Remark \\
\hline Model & $8.096 \mathrm{E}+006$ & 9 & $8.995 \mathrm{E}+005$ & 125.81 & $<0.0001$ & & Significant \\
\hline$v c$ & $3.231 \mathrm{E}+006$ & 1 & $3.231 \mathrm{E}+006$ & 451.94 & $<0.0001$ & 39.32 & Significant \\
\hline$f$ & $1.905 \mathrm{E}+006$ & 1 & $1.905 \mathrm{E}+006$ & 266.49 & $<0.0001$ & 23.18 & Significant \\
\hline$a p$ & $2.260 \mathrm{E}+006$ & 1 & $2.260 \mathrm{E}+006$ & 316.15 & $<0.0001$ & 27.50 & Significant \\
\hline$v c \times f$ & $3.084 \mathrm{E}+005$ & 1 & $3.084 \mathrm{E}+005$ & 43.14 & $<0.0001$ & 3.75 & Significant \\
\hline$v c \times a p$ & $3.628 \mathrm{E}+005$ & 1 & $3.628 \mathrm{E}+005$ & 50.74 & $<0.0001$ & 4.42 & Significant \\
\hline$f \times a p$ & $3.017 \mathrm{E}+005$ & 1 & $3.017 \mathrm{E}+005$ & 42.20 & $<0.0001$ & 3.67 & Significant \\
\hline$v c^{2}$ & 16712.25 & 1 & 16712.25 & 2.34 & 0.1447 & 0.20 & Insignificant \\
\hline$f^{2}$ & 22367.50 & 1 & 22367.50 & 3.13 & 0.0949 & 0.27 & Insignificant \\
\hline$a p^{2}$ & 11015.88 & 1 & 11015.88 & 1.54 & 0.2314 & 0.13 & Insignificant \\
\hline Error & $1.215 \mathrm{E}+005$ & 17 & 7149.60 & & & & \\
\hline Total & $8.217 \mathrm{E}+006$ & 26 & & & & 100 & \\
\hline
\end{tabular}

just $7.89 \%$. From Table 8 it can be noted that the cutting speed is the most preponderant parameter which affect the cutting power with the contribution of about $39.32 \%$.
The second factor influencing $P_{c}$ is the depth of cut with a contribution of about $27.50 \%$. Although, the feed rate, its effect is less important and its contribution is $23.18 \%$. 
To better view the results of the analysis of variance, a Pareto graph was built (Fig. 2). This figure ranks the cutting parameters and their interactions of their growing influence on the surface roughness $(R a)$, cutting force $(F c)$, specific cutting force $(K c)$, and power $(P c)$. The effects were standardized ( $F$-value) for a better comparison. Standardized values in this figure are obtained by dividing the effect of each factor by the error on the estimated value of the corresponding factor. The more standardized the effect, the higher factor considered influence.

If the $F$-table values are greater than 4.45 ; the effects are significant. By cons, if the values of $F$-table are less than 4.45; the effects are not significant. The confidence interval chosen is $95 \%$.

\subsection{Regression equation for various responses}

The functional relationship between the dependent variables $(R a, F c, K c$, and $P c$ ) and the investigated independent variables (cutting speed, feed rate and depth of cut) were represented joined with the correlation coefficients $R^{2}$ which proves the regression accuracy. The different quadratic models obtained from statistical analysis can be used to predict the surface roughness, cutting force, specific cutting force and cutting power according to the studied factors. The models and its determination coefficients obtained for different cutting phenomena are presented in Eqs. (6)-(9).

$$
\begin{aligned}
& R a=0.69-0.003 v c-1.79 f+0.42 a p+62.06 f^{2}-0.29 a p^{2} \\
& +0.007 v c \times f+0.004 v c \times a p-6.70 f \times a p \\
& R^{2}=0.9566
\end{aligned}
$$

$F c=65.56+0.416 v c-623.61 f-102.02 a p-0.00037 v c^{2}$

$+2674.30 f^{2}+167.56 a p^{2}-1.13 v c \times f-0.34 v c \times a p$

$$
+1993.92 f \times a p
$$

$R^{2}=0.9934$

$K c=6255.76+1.51 V c-24825.52 f-5137.25 a p$

$-0.002 V c^{2}+57157.89 f^{2}+3194.87 a p^{2}-5.62 V c \times f$

$-1.58 V c \times a p+5385.97 f \times a p$

$R^{2}=0.8829$

$P c=688.83-0.261 v c-6258.32 f-1403.89 a p-0.003 v c^{2}$

$+9540.10 f^{2}+476.09 a p^{2}+15.17 v c \times f+4.39 v c \times a p$

$+6606.80 f \times a p$

$R^{2}=0.9852$

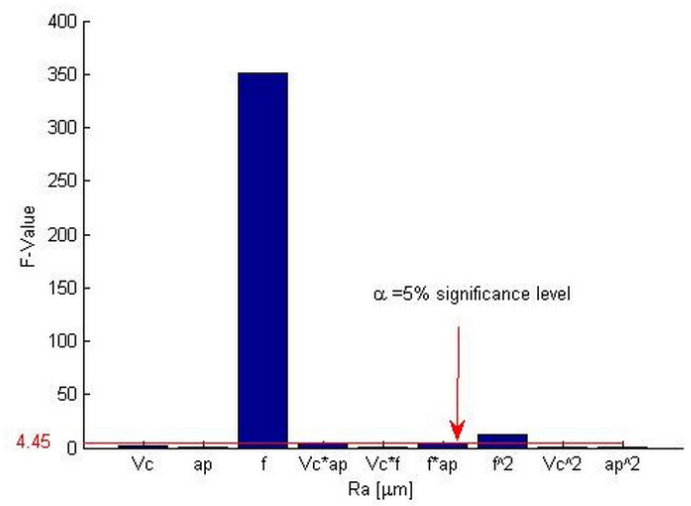

(a)

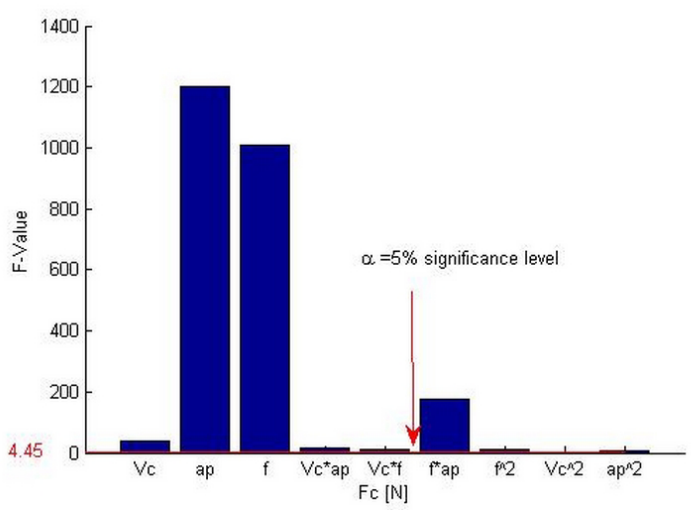

(b)

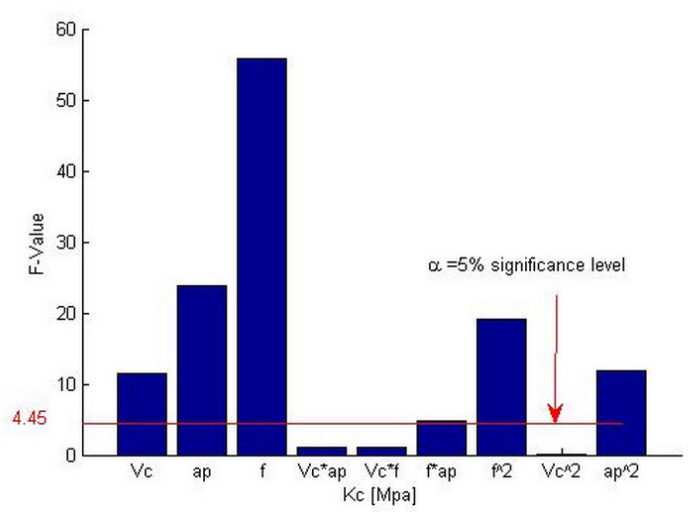

(c)

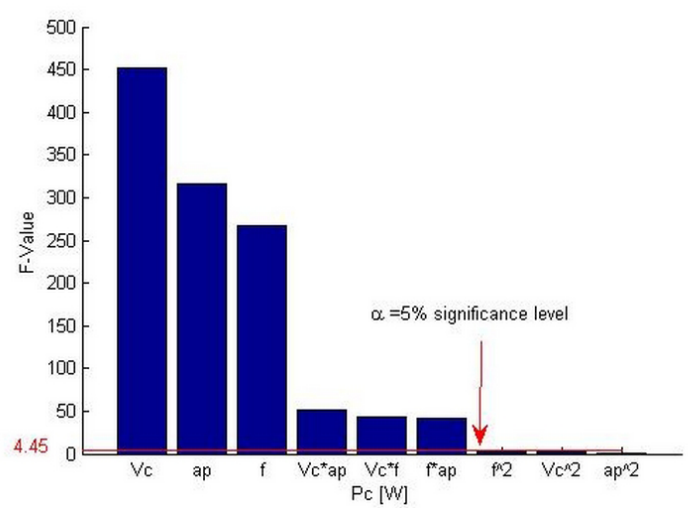

(d)

Fig. 2 Graphs of Pareto, for effect cutting parameters on: (a) surface roughness, (b) cutting force, (c) specific cutting force, and (d) power. 
The differences between experimental and predicted values are presented in Fig. 3 (a)-(d). The normal probability plots of predicted response for the surface roughness, cutting force, specific cutting force, machining power are plotted respectively in Fig. 4 (a)-(d).

The data closely follows the straight line. The null hypothesis is that the data distribution law is normal and the alternative hypothesis is that it is non-normal. Using the $P$-value which is greater than $\alpha=0.05$ (level of significance), the null hypothesis cannot be rejected (i.e., the data follow a normal distribution). Fig. 5 and Fig. 6 show the comparison between the predicted and measured values of surface roughness $(R a)$ and cutting force $(F c)$. It implies that the models proposed are adequate.

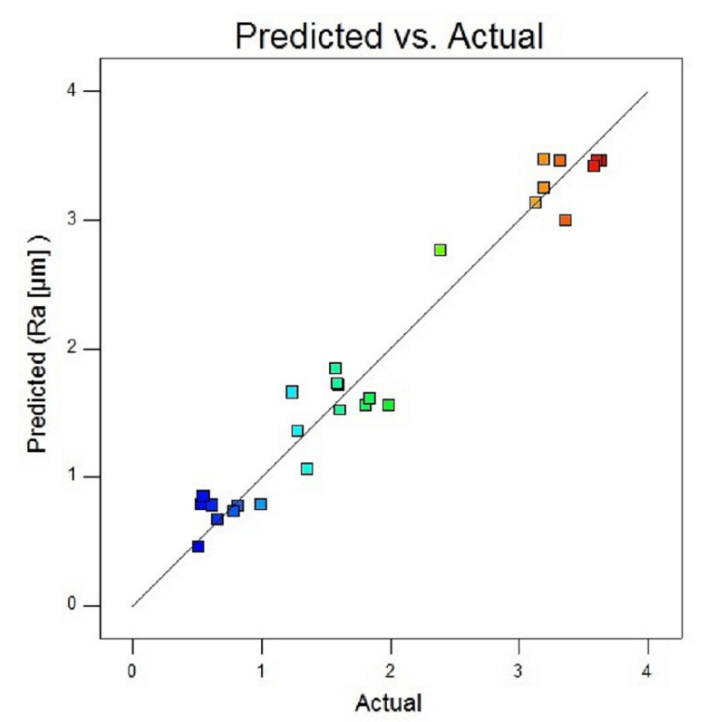

(a)

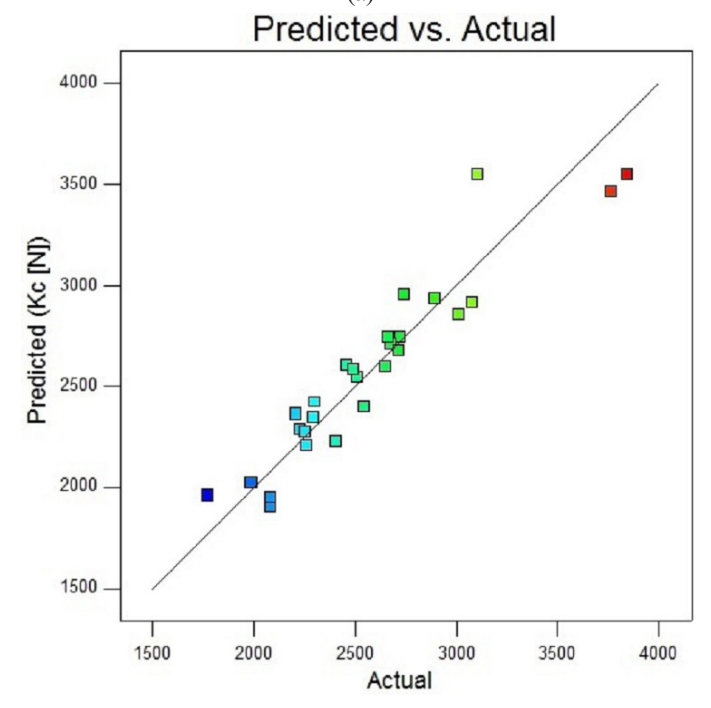

(c)

\subsection{Responses surface analysis}

\subsubsection{Surface roughness}

The estimated response surface for the surface roughness with respect to the cutting parameters $(v c, f$ and $a p)$ presented in Fig. 7 shows that the feed rate is the most influencing parameter that affects the machined surface. It can be clearly noted that with a low feed rate, the machined surface have a better surface quality this result has been reported by Hessainia et al. [18] and Noordin et al. [19].

The increase in surface roughness when increasing of cutting speed can be explained by the presence of microwelds on machined surface due to high heat at cutting zone and the breaking of BUE Fig. 8 (a). Furthermore, increasing the cutting speed causes an increase in surface roughness

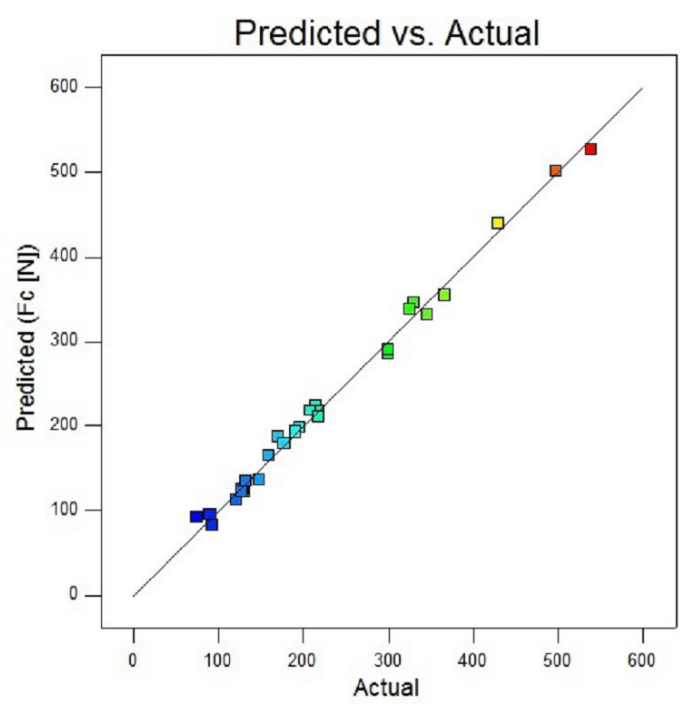

(b)

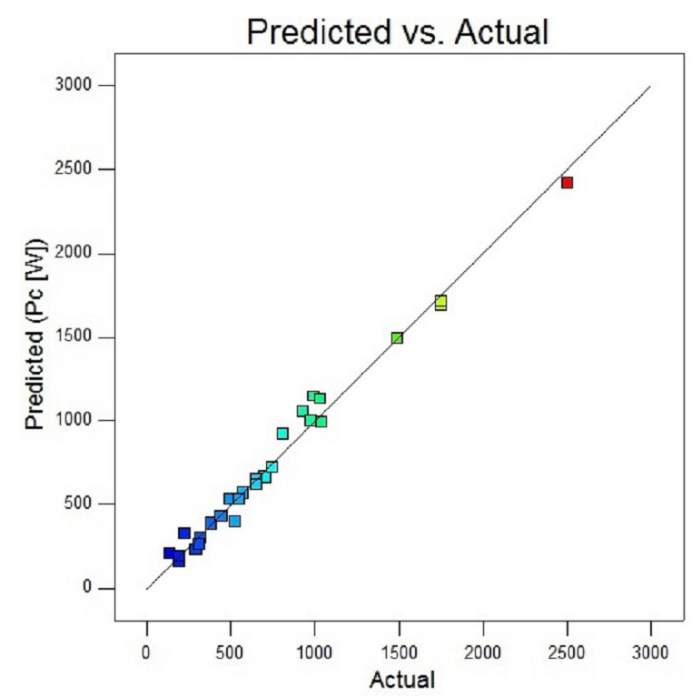

(d)

Fig. 3 Predicted vs actual values for; (a) $R a$, (b) $F c$, (c) $K c$, and (d) $P c$ 


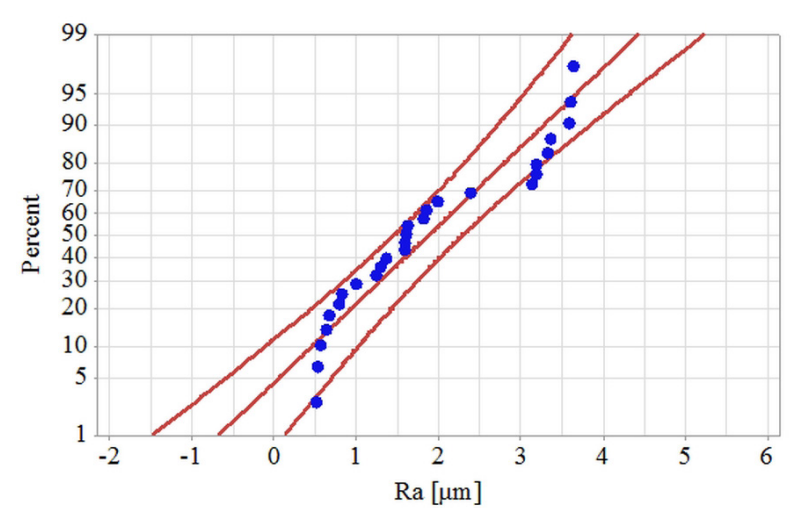

(a)

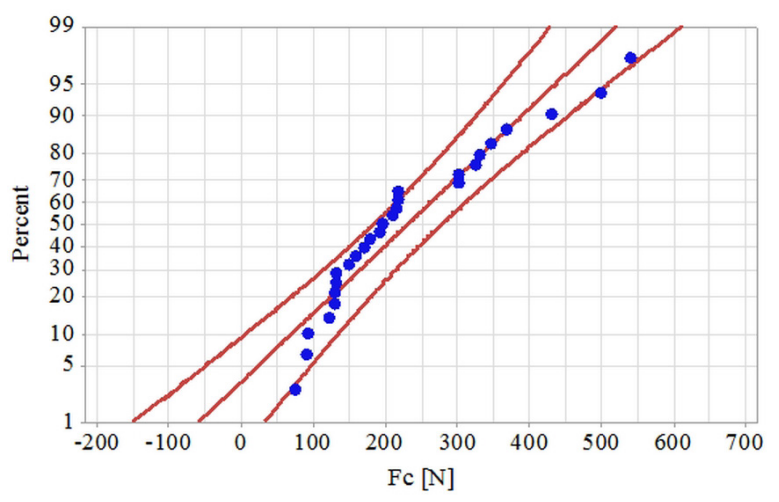

(b)

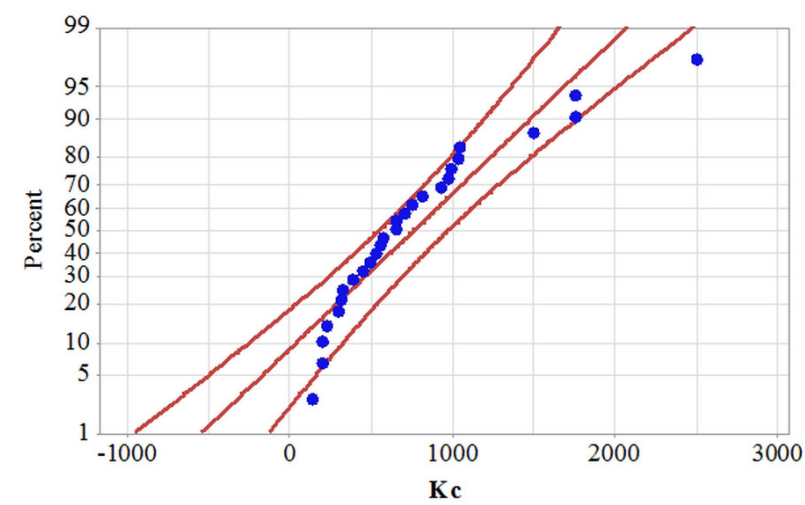

(c)

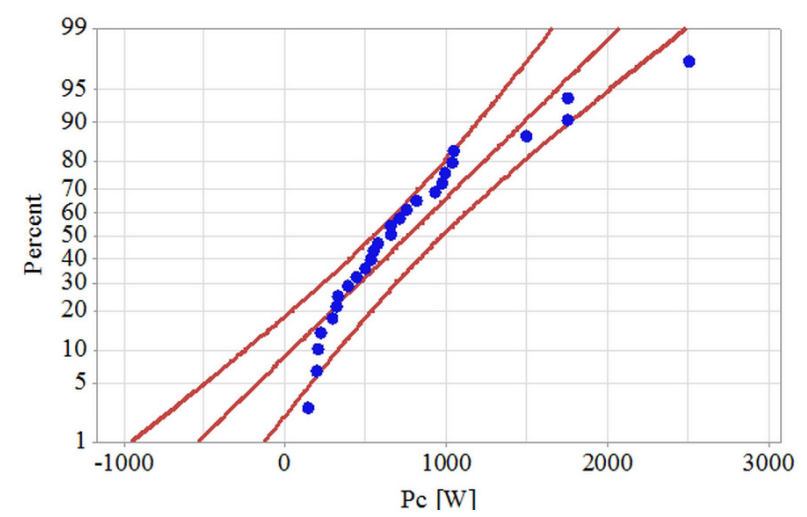

(d)

Fig. 4 Normal probability plot: (a) $R a$, (b) $F c$, (c) $K c$, and (d) $P c$

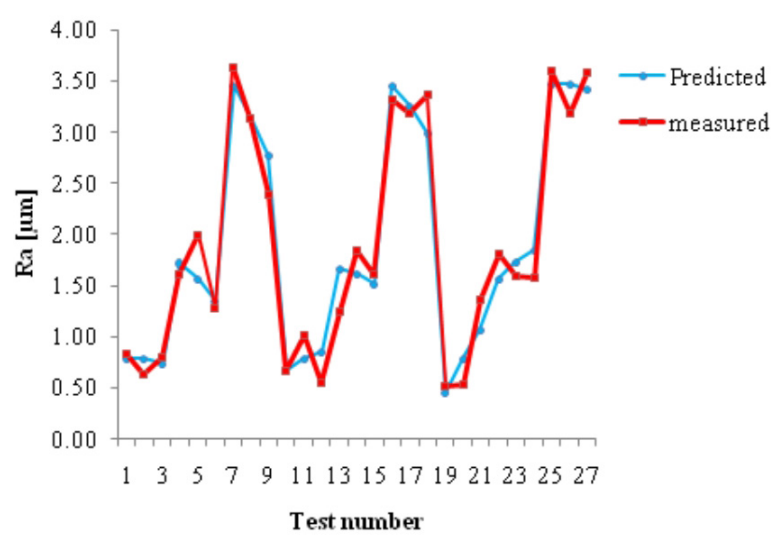

Fig. 5 Comparison between the predicted and measured values for the surface roughness $(R a)$.

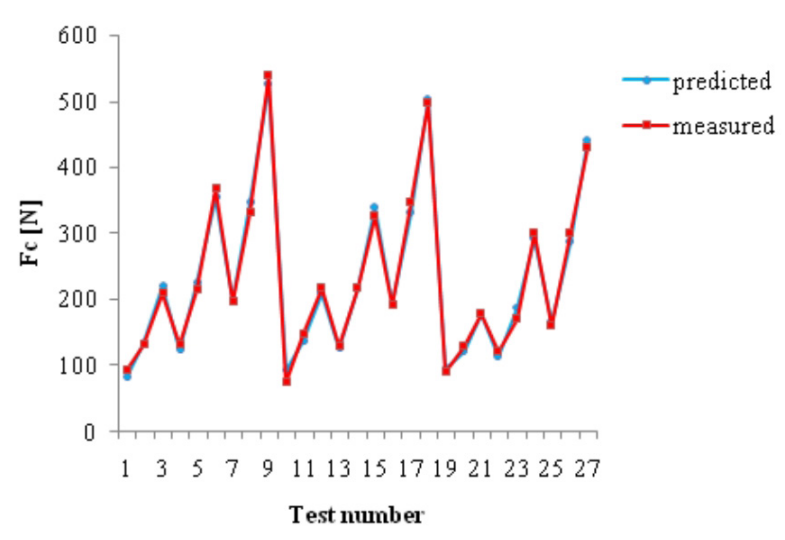

Fig. 6 Comparison between the predicted and measured values for the cutting force $(F c)$.

because the cutting tool nose wears increases and causing the poor surface finish (Ezugwu and Lim [20]). Higher surface roughness value in AISI 304 can be explained by high ductility nature of austenitic stainless steel which increases the tendency to form a large and unstable BUE producing the poor surface finish (Kopač and Bahor [21]). The continuous friction at the tool/chip interface increases the temperature. Consequently, the high ductile material such as AISI 304 and at high deformation mode can be stick on the tool bec and on the rake face causing BUE or microwelding spots.

A high values of surface roughness noted in small value of cutting speed could be caused by the presence of Built-Up Edge (Fig. 8 (b)) on the rake face due to the high ductility of austenitic stainless steel (Gökkaya [22] and Paro et al. [23]).

\subsubsection{Tangential cutting force}

The 3D surface plot displayed in Fig. 9, illustrates the effect of cutting parameters on cutting force. The observed variation of the cutting force as a function of the cutting conditions was linear and found to be 


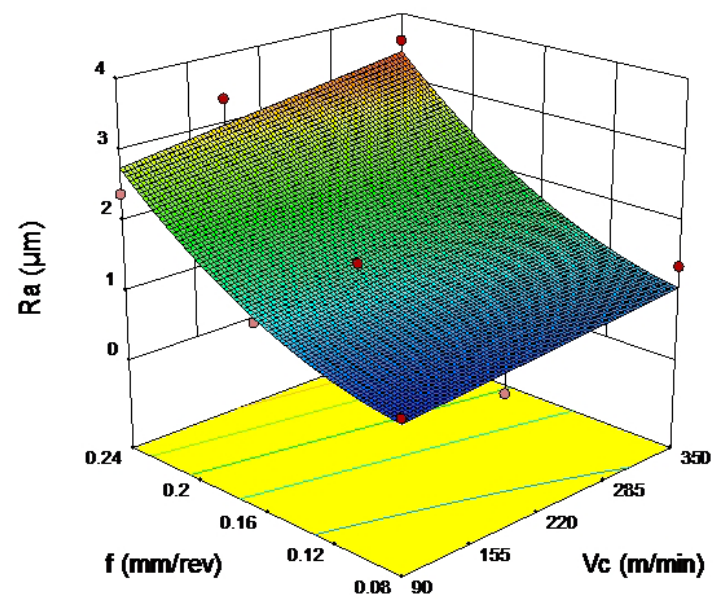

(a)

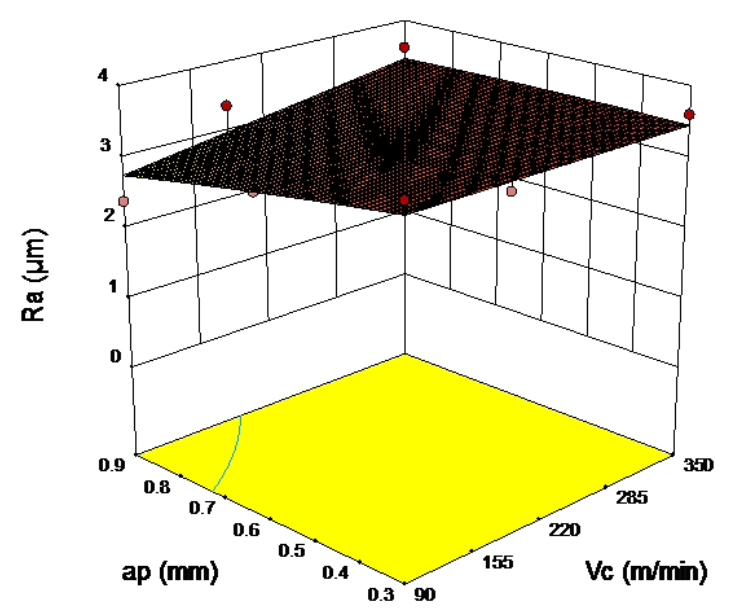

(b)

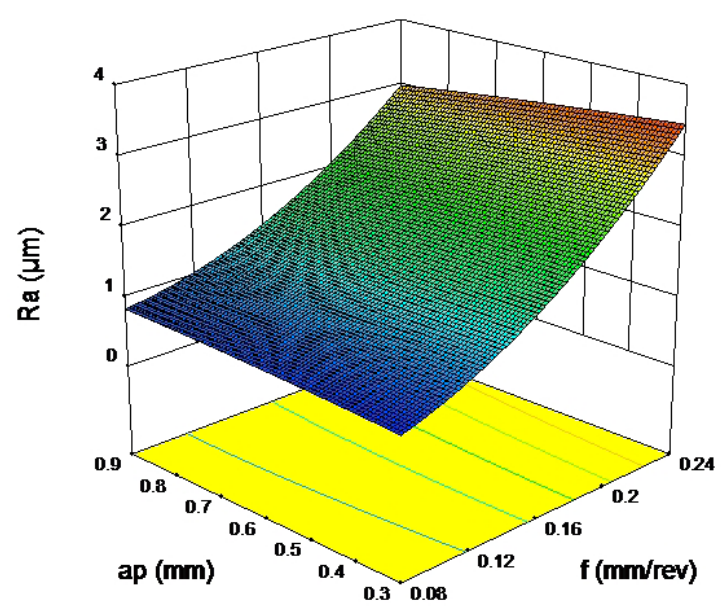

(c)

Fig. 7 Surface and contour plots of $(R a)$ (a) $a p=0.9 \mathrm{~mm}$, (b) $f=0.24 \mathrm{~mm} / \mathrm{rev}$, (c) $V_{c}=180 \mathrm{~m} / \mathrm{min}$

increase with the increasing of feed rate and of depth of cut. This behavior is due to the increase of ship section (Cassier et al. [24]). According to the surface plot, it can be observed that the feed rate has a small influence

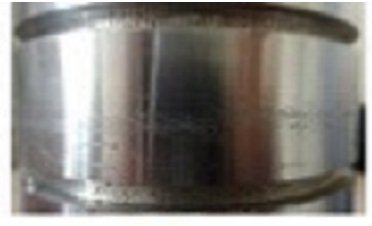

(a)

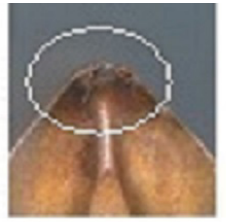

(b)
Fig. 8 Representation of the micro-weld on the machined surface and the Built-Up Edge on the cutting insert.

(a) Micro-welds, (b) Built-Up Edge

on FC compared with depth of cut and that's confirmed in ANOVA previously. Furthermore, cutting speed affect slightly tangential force with increasing in cutting speed $F_{C}$ decreases because the temperature increases at the cutting zone which leads to the softening of workpiece. This allows removing the material at lower cutting force. Similar observation has been reported by El-Tamimi and El-Hossainy [25] and Wagh et al. [26], recording a high forces at lower cutting speed because the chip remains for long time in the tool rake face which increases the toolchip contact length which in turn increases the friction between the tool and chip that resulted in higher forces.

\subsubsection{Power and specific cutting force}

The variation of the power with different cutting parameters presented in Fig. 10 shows that power increase with the increasing of different cutting parameters. It was clear from surface plot that the depth of cut (ap) is the most preponderant parameter affecting the cutting power. When the depth of cut ( $a p$ ) increase, the tangential force increase.

The influence of studied cutting parameters ( $v c, f$ and $a p$ ) on specific cutting force has been illustrated in Fig. 11. It has been found that the feed rate affects considerably $K c$ when feed rate increase, the $K c$ decrease (Kaczmarek [27]). It seems that an increase of the feed rate generates a higher friction between the material been removed and the cutting tool. It is clear from analysis that higher cutting speed with high feed rate is beneficial to reduce the cutting force and consequently decreasing the specific cutting force. This can be explained by the generation of heat in the cutting speed range caused by the toolchip friction due to the low thermal conductivity of the steel ASI 304 (Table 1).

\subsubsection{Material Removal Rate}

Fig. 12 presents the variation of Material Removal Rate (Eq. (3)) with different cutting conditions. It can be observed that MRR increase with the increasing of ( $v c, f$ and $a p$ ). However, the depth of cut was the most 


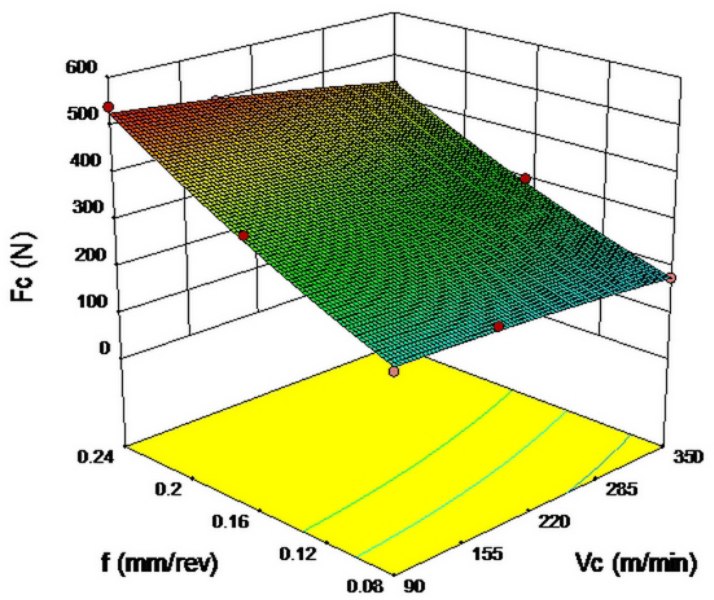

(a)

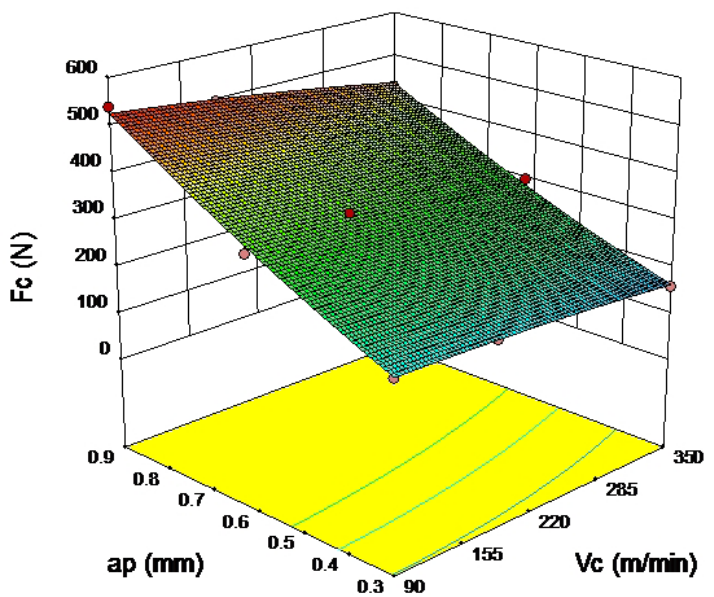

(b)

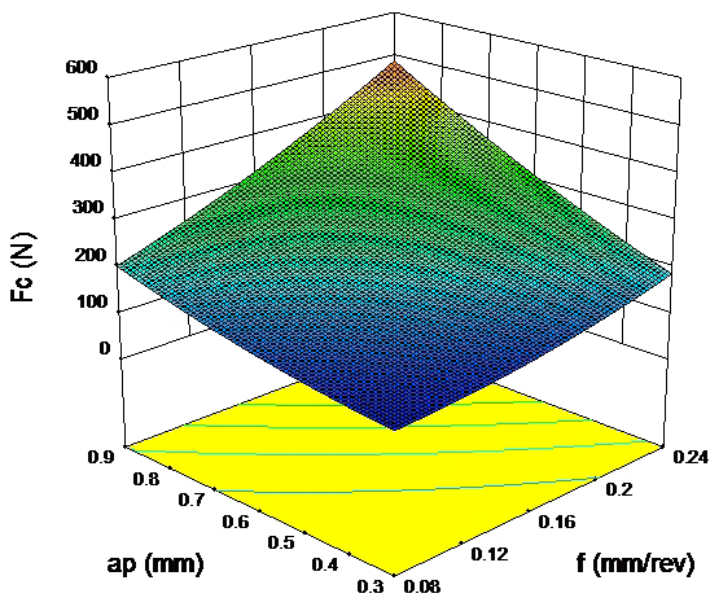

(c)

Fig. 9 Surface and contour plots of $(F c)$ (a) $a p=0.9 \mathrm{~mm}$, (b) $f=0.24 \mathrm{~mm} / \mathrm{rev}$, (c) $v c=220 \mathrm{~m} / \mathrm{min}$

preponderant parameter affecting MRR followed by feed rate and cutting speed. On the other hand, the depth of cut is generally limited by the couple of tool-workpiece.

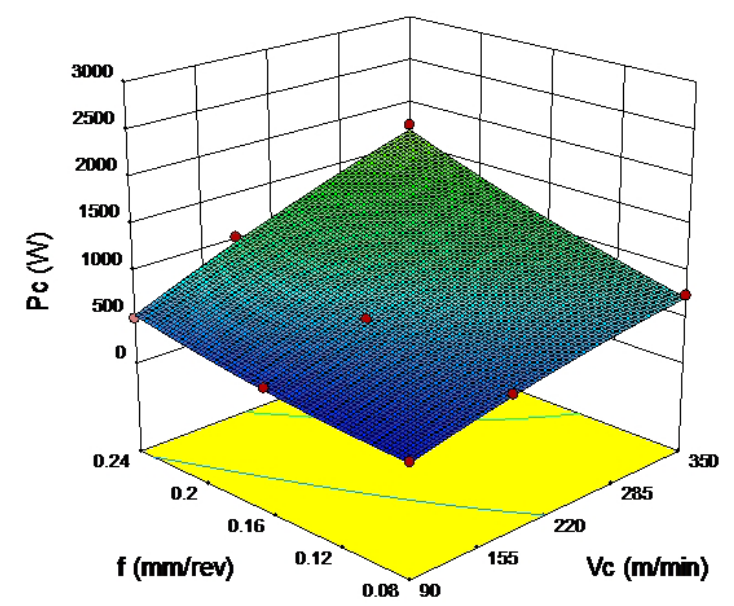

(a)

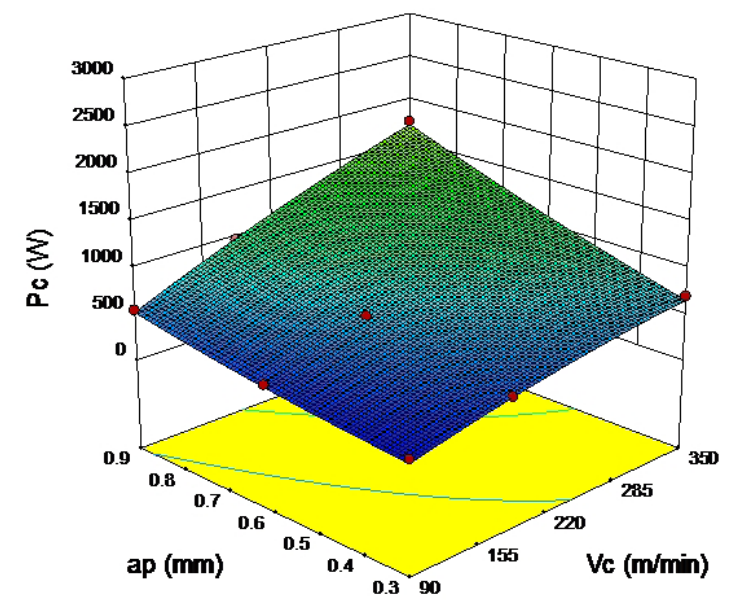

(b)

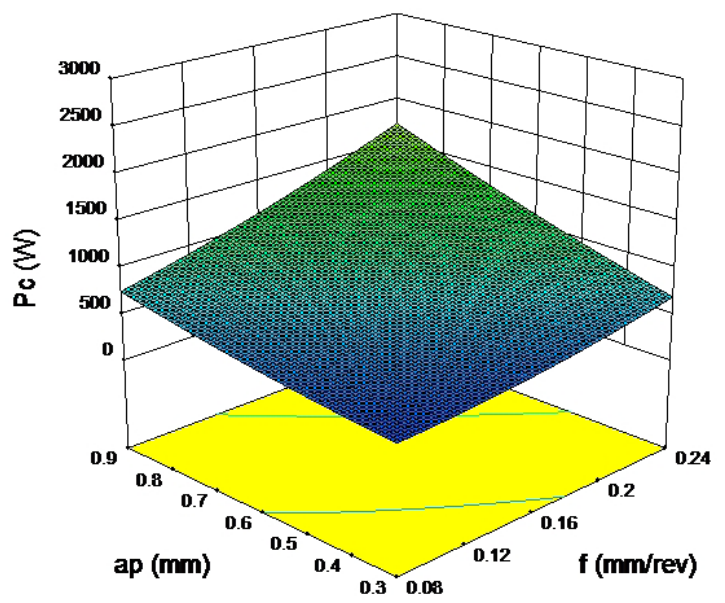

(c)

Fig. 10 Surface and contour plots of $(P c)$ (a) $a p=0.6 \mathrm{~mm}$, (b) $f=0.16 \mathrm{~mm} / \mathrm{rev}$, (c) $v c=220 \mathrm{~m} / \mathrm{min}$

In the case where the depth of cut is at the high permitted level, the feed rate becomes the important parameter affecting the MMR. 


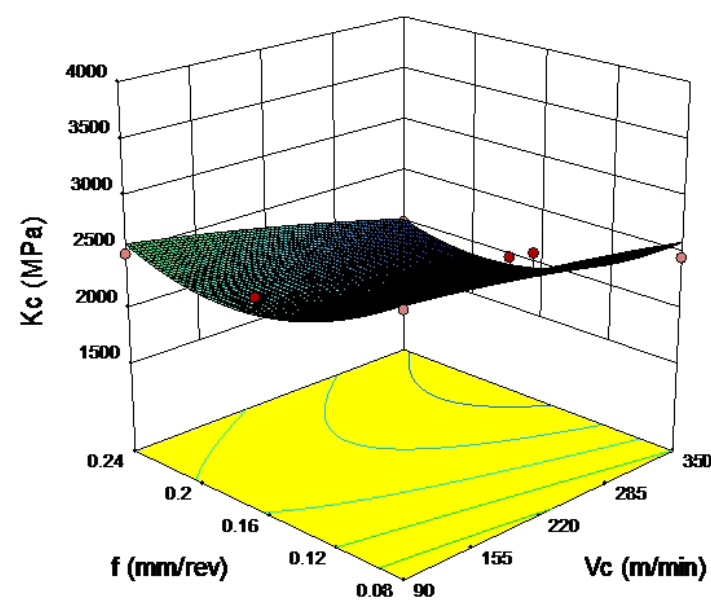

(a)

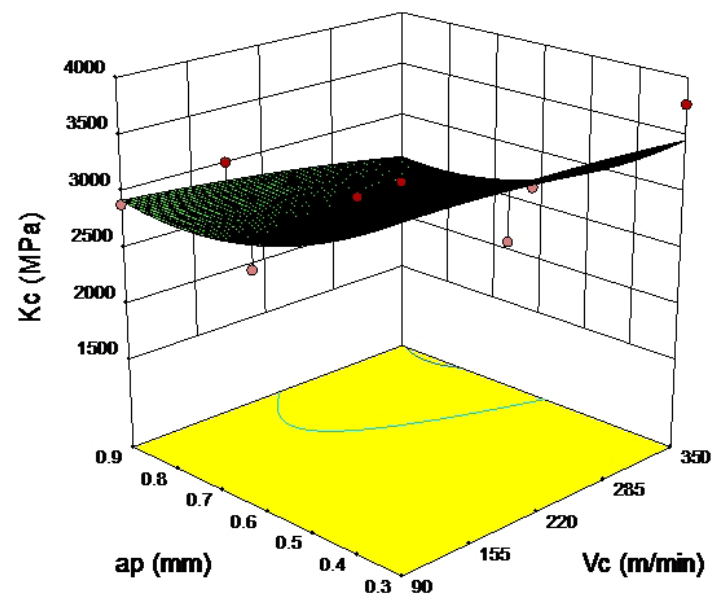

(b)

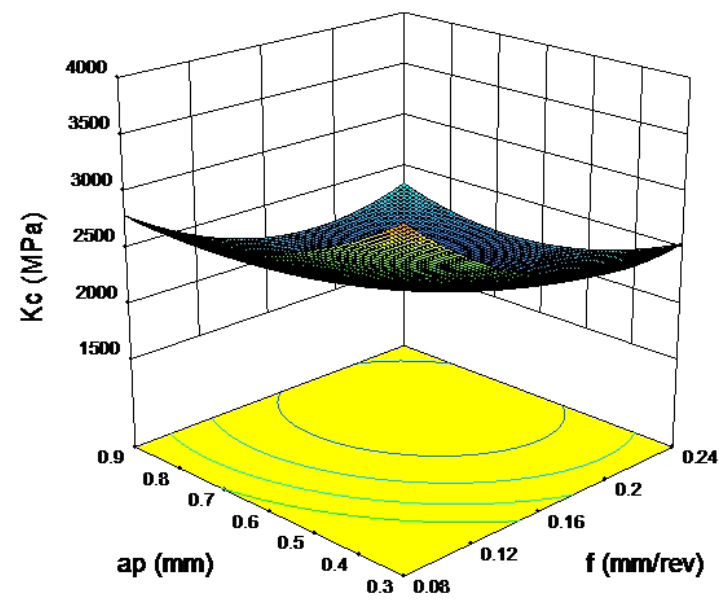

(c)

Fig. 11 Surface and contour plots of $(K c)$ (a) $a p=0.9 \mathrm{~mm}$, (b) $f=0.08 \mathrm{~mm} / \mathrm{rev}$, (c) $v c=220 \mathrm{~m} / \mathrm{min}$

\section{Confirmation tests}

The confirmation tests were performed for surface roughness, cutting force, specific cutting force and cutting power in order to validate the obtained mathematical models

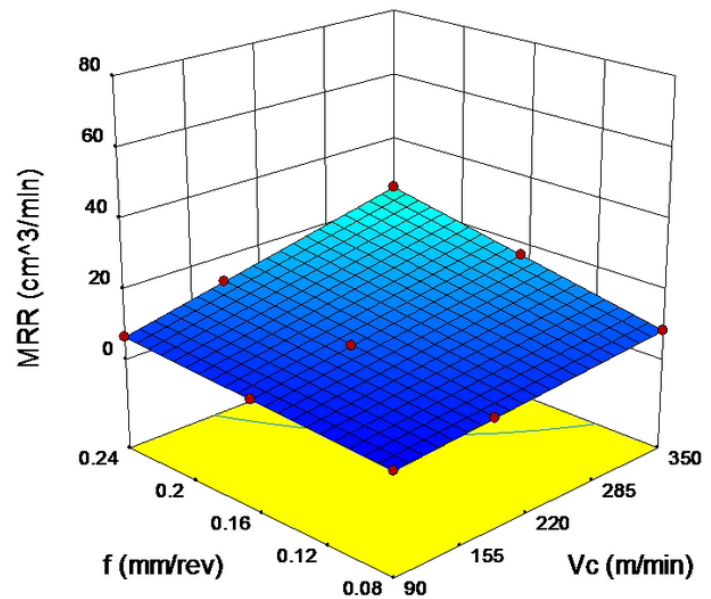

(a)

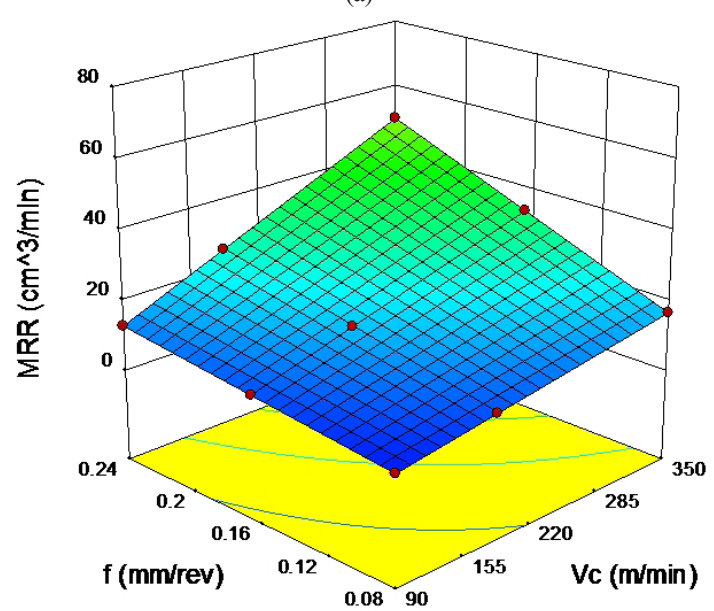

(b)

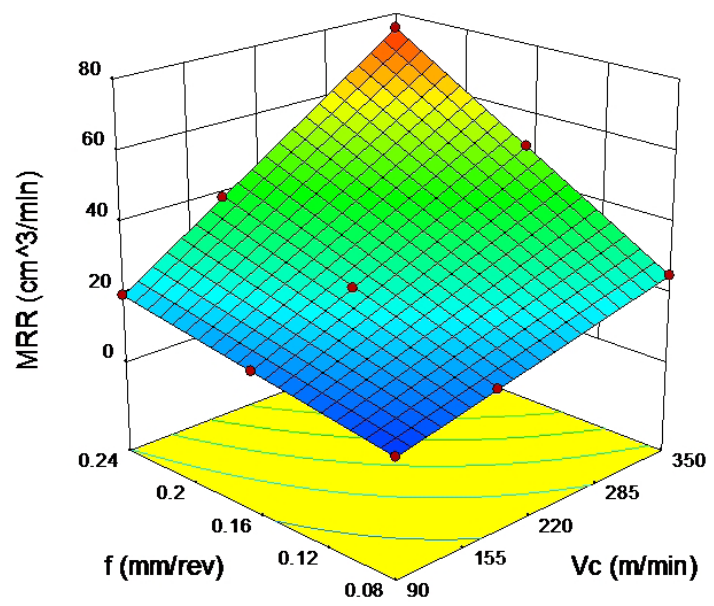

(c)

Fig. 12 Surface and contour plots for MRR (a) $a p=0.3 \mathrm{~mm}$, (b) $a p=0.6 \mathrm{~mm}$, (c) $a p=0.9 \mathrm{~mm}$

proposed by the Eqs. (6)-(9). The cutting parameters used in the turning confirmation tests were presented in the Table 9. The Table 10 shows the results obtained where a comparison was done between the predicted values from the model developed in the present work (Eqs. (6)-(9)), with the experimental data. 
Table 9 Cutting conditions used in turning confirmation tests.

\begin{tabular}{lccc}
\hline Test $\mathrm{N}^{\circ}$ & $v c(\mathrm{~m} / \mathrm{min})$ & $f(\mathrm{~mm} / \mathrm{rev})$ & $a p(\mathrm{~mm})$ \\
\hline T1 & 160 & 0.08 & 0.3 \\
T2 & 230 & 0.08 & 0.3 \\
T3 & 230 & 0.16 & 0.3 \\
\hline
\end{tabular}

Table 10 Confirmation tests.

\begin{tabular}{|c|c|c|c|c|c|}
\hline \multicolumn{3}{|c|}{ Test $\mathrm{N}^{\circ}$} & 1 & 2 & 3 \\
\hline \multirow{12}{*}{ 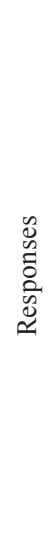 } & \multirow{3}{*}{$R a$} & Actual & 0.69 & 0.61 & 1.56 \\
\hline & & Predicted & 0.68 & 0.60 & 1.63 \\
\hline & & Error $(\%)$ & 0.45 & 1.67 & 4.48 \\
\hline & \multirow{3}{*}{$F_{c}$} & Actual & 84.95 & 88.04 & 120.02 \\
\hline & & Predicted & 90.11 & 94.96 & 123.44 \\
\hline & & Error (\%) & 6.07 & 7.86 & 2.84 \\
\hline & \multirow{3}{*}{$K c$} & Actual & 3539.58 & 3668.33 & 2500.41 \\
\hline & & Predicted & 3552.26 & 3536.52 & 2673.75 \\
\hline & & Error (\%) & 0.35 & 3.59 & 6.93 \\
\hline & \multirow{3}{*}{$P \mathrm{c}$} & Actual & 265.55 & 344.82 & 470.07 \\
\hline & & Predicted & 302.90 & 366.12 & 486.46 \\
\hline & & Error $(\%)$ & 14.06 & 6.17 & 3.48 \\
\hline
\end{tabular}

According to the analysis of Table 10 it can be noted that the calculated error for surface roughness $R a$ is (maximum value $4.48 \%$ and minimum $0.45 \%$ ), for the cutting force $F_{c}$ (maximum value $7.86 \%$ and minimum $2.84 \%$ ), for the specific cutting force $K c$ (maximum value $6.93 \%$ and minimum $0.35 \%$ ) and for the cutting power $P c$ (maximum value $14.06 \%$ and minimum $3.48 \%$ ). Therefore, it can be considered that the Eqs. (6)-(9) correlate the evolution of surface roughness, cutting force, specific cutting force and cutting power with the cutting parameters with a reasonable degree of approximation (see Fig. 13).

In addition to the results shown in Table 10 for surface roughness, a noncontact threedimensional white light interferometer, Altisurf 500, with a sensor having a dynamic range of $50 \mathrm{~nm}-300 \mu \mathrm{m}$, was employed to measure and investigate the surface topography.

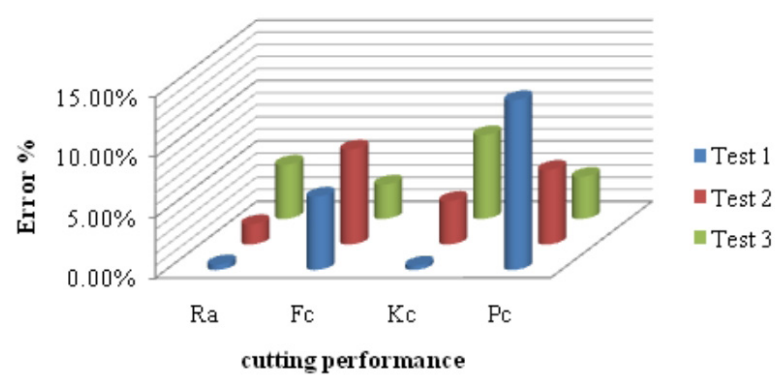

Fig. 13 Error between predicted values and experimental values.
Fig. 14 shows the Profiles of surface roughness after machining with various cutting speeds and feed rates. For large feed rate $(f=0.20 \mathrm{~mm} / \mathrm{rev})$ (see Fig. 14 (b) and (c)) the shape of profile is periodic, with well-defined peaks and valleys, and the spacing between two peaks is equal to the value of feed rate $(\mathrm{mm} / \mathrm{rev})$, similar results were reported by Krolczyk and Legutko [28] and Chen et al. [29] and the surface roughness $(R a)$ is higher compared to those machined with low feed rates (see Fig. 14 (a) and (d)) where the furrows and the surface roughness $(R a)$ are small.

\section{Multiple responses optimization}

The desirability function approach is one of the most widely used methods in the industry for the optimization of multiple response processes. A useful class of desirability function was proposed by Derringer and Suich [30].

In the present study, desirability function optimization of the RSM has been employed for surface roughness, cutting force, specific cutting force, cutting power and Material Removal Rate optimizations. During the optimization process, the aim was to find the optimal values of cutting parameters in order to minimize the values of surface roughness (quality optimization), and maximize the value of Material Removal Rate (Productivity optimization).

Table 11 shows the constraint for optimization of the above cited cutting parameter.

As shown in Table 11, three configurations were studied; optimization of quality that is recommended for better surface quality but with low productivity with desirability of 1 . The second is the optimization of productivity, this optimization is to increase productivity but against one loses part surface quality with desirability of 1 .

The last optimization is a compromise between surface quality and productivity that we are interested because it assembles the best surface quality and maximum productivity.

Optimum cutting parameters obtained for this aims were found to be cutting speed of $350 \mathrm{~m} / \mathrm{min}$, feed rate of $0.088 \mathrm{~mm} / \mathrm{rev}$ and depth of cut of $0.9 \mathrm{~mm}$. The optimized values of ( $R a, F c$ and MRR) were respectively $(1.097 \mu \mathrm{m}$, 187.537 N, and $27.577 \mathrm{~cm}^{3} / \mathrm{min}$ ).

Table 12 summarizes the results for each type of optimization.

Graphic ramp function for $R a$ and MRR overall desirability is shown in Fig. 15. In this figure the points in red on the cutting velocity curves, feed rate and cutting depth are defining the optimal values. The optimal value 


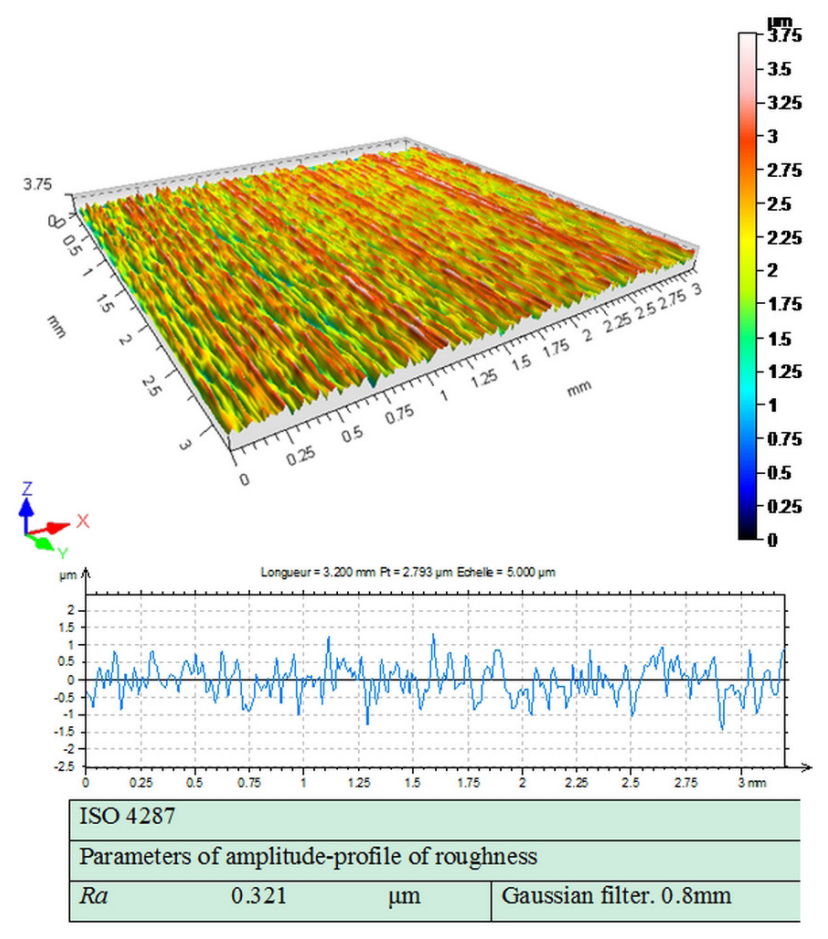

(a)

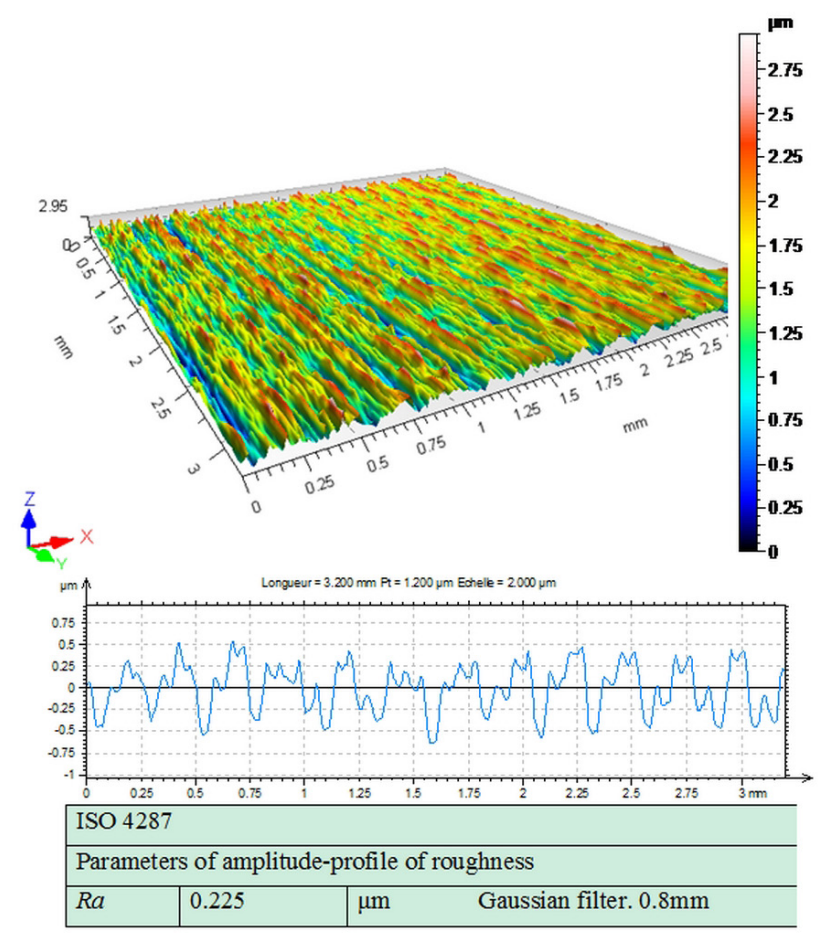

(c)

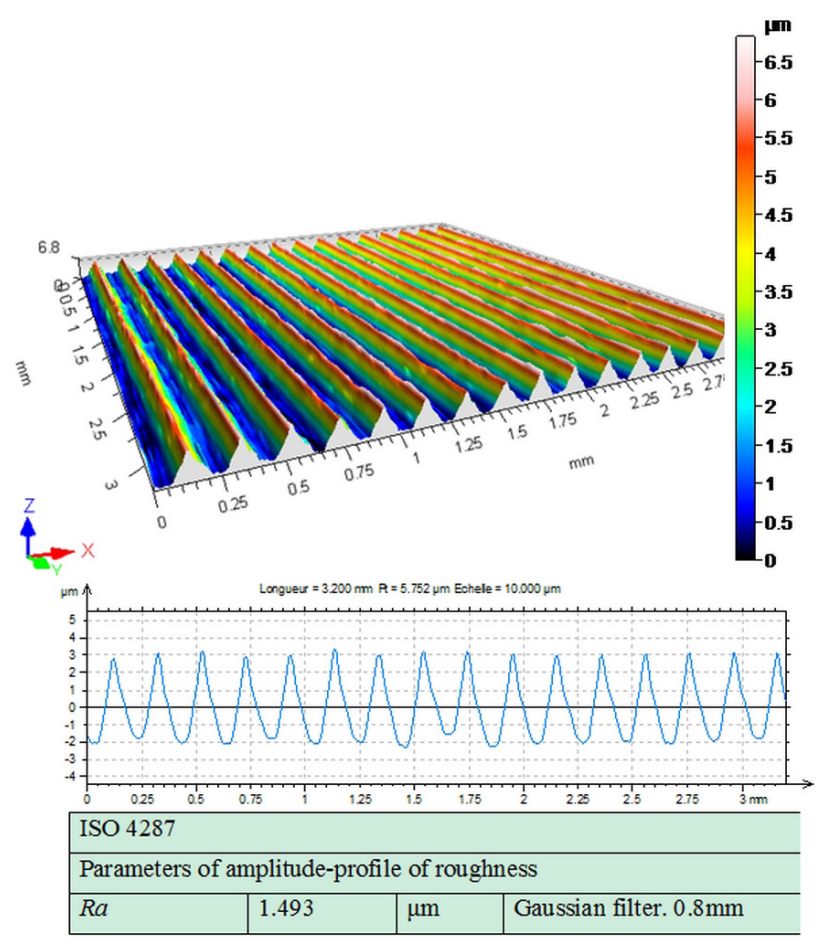

(b)

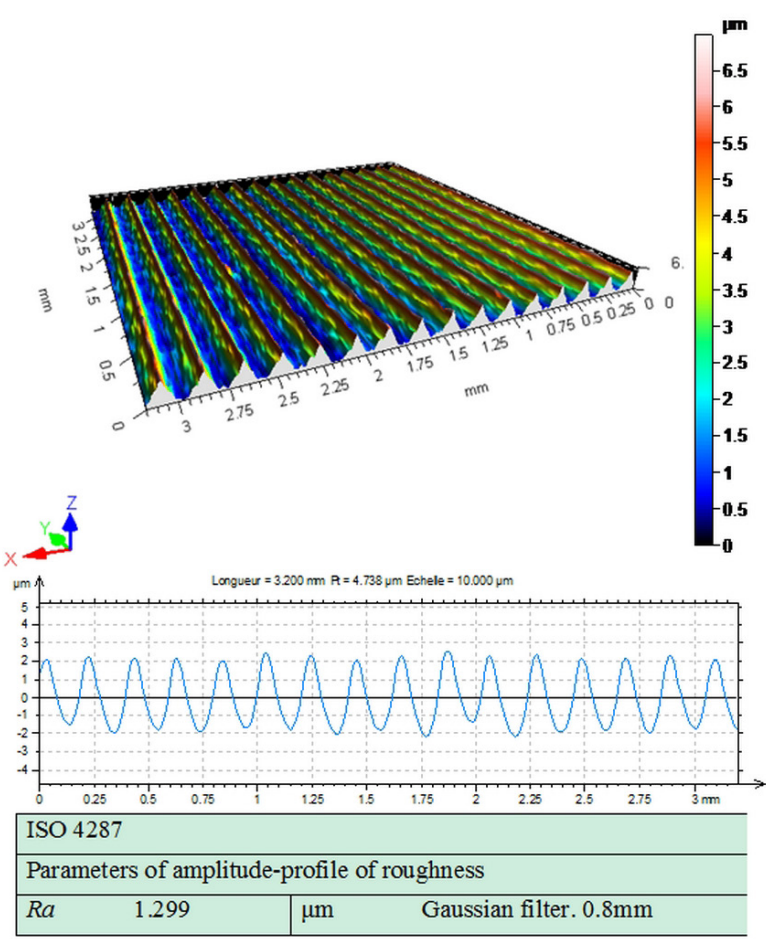

(d)

Fig. $142 \mathrm{D}$ and 3D surface roughness (a) $v c=140 \mathrm{~m} / \mathrm{min}, f=0.08 \mathrm{~mm} / \mathrm{rev}, a p=0.3 \mathrm{~mm}$, (b) $v c=140 \mathrm{~m} / \mathrm{min}, f=0.2 \mathrm{~mm} / \mathrm{rev}, a p=0.3 \mathrm{~mm}$, (c) $v c=280 \mathrm{~m} / \mathrm{min}, f=0.08 \mathrm{~mm} / \mathrm{rev}, a p=0.3 \mathrm{~mm}$, (d) $v c=280 \mathrm{~m} / \mathrm{min}, f=0.2 \mathrm{~mm} / \mathrm{rev}, a p=0.3 \mathrm{~mm}$

corresponding response namely $R a$ and MRR is also exposed by blue dot on the curves of the above.

Fig. 16 presents the bar graph of desirability for the cutting conditions and the responses together with a combined desirability $=0.727$.

\section{Conclusions}

In this study, $\mathrm{L}_{27}$ orthogonal array Taguchy design was used to study the influence of cutting parameters on surface roughness, cutting force, specific cutting force, cutting power and Material Removal Rate during the turning 
Table 11 Constraint for optimization of cutting conditions.

\begin{tabular}{|c|c|c|c|c|c|c|}
\hline \multirow[b]{2}{*}{ Name } & \multirow[b]{2}{*}{ ర్ర } & \multirow[b]{2}{*}{ 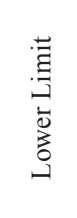 } & \multirow[b]{2}{*}{ 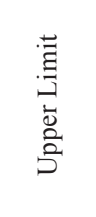 } & \multicolumn{3}{|c|}{ Importance } \\
\hline & & & & 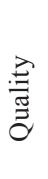 & 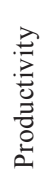 & $\begin{array}{l}\vec{\Xi} \\
\text { है } \\
\text { हैं }\end{array}$ \\
\hline$v c(\mathrm{~m} / \mathrm{min})$ & in range & 90 & 350 & 3 & 3 & 3 \\
\hline$f(\mathrm{~mm} / \mathrm{rev})$ & in range & 0.08 & 0.24 & 3 & 3 & 3 \\
\hline ap (mm) & in range & 0.3 & 0.9 & 3 & 3 & 3 \\
\hline$R a(\mu \mathrm{m})$ & Minimize & 0.51 & 3.63 & 5 & - & 5 \\
\hline$F_{c}(\mathrm{~N})$ & Minimize & 74.5 & 538.58 & - & - & 5 \\
\hline $\operatorname{MRR}\left(\mathrm{cm}^{3} / \mathrm{min}\right)$ & Maximize & 25.12 & 452.16 & - & 5 & 5 \\
\hline
\end{tabular}

of the AISI 304 stainless steel using the coated carbide tools. It has been found in the current study that:

- The analysis proved that the feed rate was most significant factor affecting the surface roughness.

- Cutting force initially increases with increase in depth of cut and feed rate and decreases with increase in cutting speed. This reduction is probably caused by increase in the temperature at the cutting zone which leads to the softening of workpiece.

- Feed rate has highest influence on specific cutting force to perform the machining operation followed by depth of cut and the cutting speed. At higher cutting speed and lower feed rate cutting force is smaller which in turn decreases the specific cutting force.

- The analysis shows that the cutting speed was the most parameter affecting the power followed by depth of cut and feed rate. When studied parameters increase the cutting power required to perform machining operation increases.

- The developed models are reliable and can be effectively used to predict surface roughness, cutting force, specific cutting force and cutting power for a given pair of tools and work materials and within the same range of cutting parameters because the relative error between the predicted values and the experimental results of the different responses studied is very small.

Table 12 Optimization results.

\begin{tabular}{lcccccc}
\hline & \multicolumn{3}{c}{ Cutting parameters } & \multicolumn{3}{c}{ Responses } \\
Optimization & $v c$ & $f$ & $a p$ & Ra & Fc & MRR \\
\hline Productivity & 350 & 0.24 & 0.9 & - & - & 75.60 \\
Quality & 350 & 0.08 & 0.3 & 0.451 & - & - \\
Combined & 350 & 0.088 & 0.9 & 1.097 & 187.52 & 27.557 \\
\hline
\end{tabular}

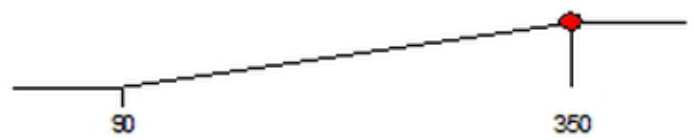

$\mathrm{A}: \mathrm{V} c=360$

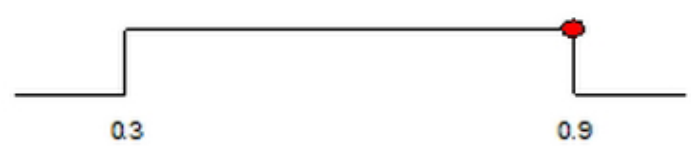

$C: 9 p=0.899998$

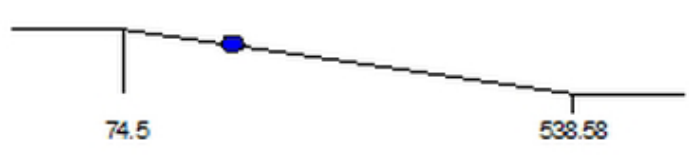

$\mathrm{Fc}=187.537$

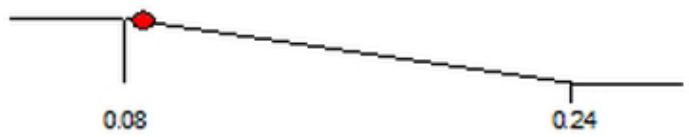

B.f $=0.087547$

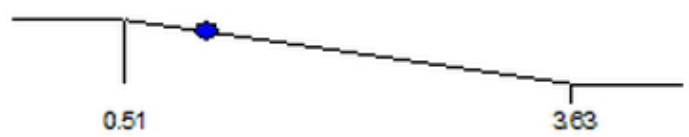

$R g=1.09604$

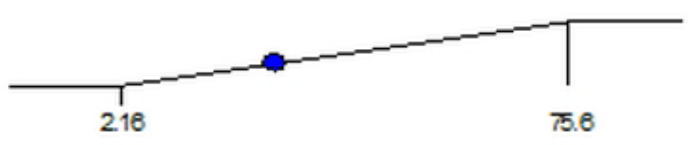

MRR $=27.572$ 


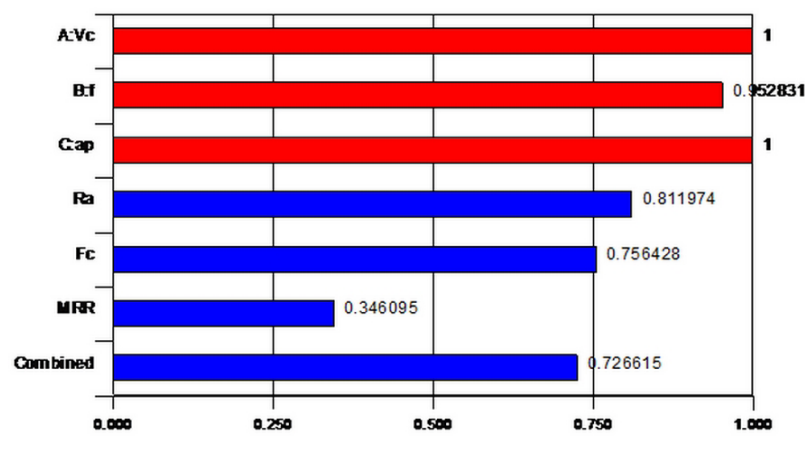

Fig.16 Bar graph of desirability (multi-objective).

\section{References}

[1] Nayak, S. K., Patro, J. K., Dewangan, S., Gangopadhyay, S. "Multi-Objective Optimization of Machining Parameters During Dry Turning of AISI 304 Austenitic Stainless Steel Using Grey Relational Analysis", Procedia Materials Science, 6, pp. 701-708, 2014.

https://doi.org/10.1016/j.mspro.2014.07.086

[2] Selvaraj, D. P., Chandramohan, P., Mohanraj, M. "Optimization of surface roughness, cutting force and tool wear of nitrogen alloyed duplex stainless steel in a dry turning process using Taguchi method", Measurement, 49, pp. 205-215, 2014.

https://doi.org/10.1016/j.measurement.2013.11.037

[3] Xavior, M. A., Adithan, M. "Determining the influence of cutting fluids on tool wear and surface roughness during turning of AISI 304 austenitic stainless steel", Journal of Materials Processing Technology, 209(2), pp. 900-909, 2009

https://doi.org/10.1016/j.jmatprotec.2008.02.068

[4] Kalidass, S., Palanisamy, P., Muthukumaran, V. "Prediction and optimisation of tool wear for end milling operation using artificial neural networks and simulated annealing algorithm", International Journal of Machining and Machinability of Materials, 14(2), pp. 142-164, 2013.

https://doi.org/10.1504/IJMMM.2013.055734

[5] Kaladhar, M., Subbaiah, K. V., Rao, C. S. "Optimization of Surface Roughness and Tool Flank Wear in Turning of AISI 304 Austenitic Stainless Steel with CVD Coated Tool", Journal of Engineering Science and Technology, 8(2), pp. 165-176, 2013.

[6] Kulkarni, A., Joshi, G., Sargade, V. G. "Design optimization of cutting parameters for turning of AISI 304 austenitic stainless steel using Taguchi method", Indian Journal of Engineering and Materials Sciences, 20, pp. 252-258, 2013. [online] Avialable at: http://nopr.niscair.res.in/handle/123456789/20960 [Accessed: 05 February 2018]

[7] Chinchanikar, S., Choudhury, S. K. "Machining of hardened steel - Experimental investigations, performance modeling and cooling techniques: A review", International Journal of Machine Tools \& Manufacture, 89, pp. 95-109, 2015.

https://doi.org/10.1016/j.ijmachtools.2014.11.002.
- The response optimization shows that to have maximum quality and outstanding productivity loss occurs and vice-versa, to overcome this problematic, the compromise should be imposed between part quality and productivity. The optimal cutting parameters found for best quality and best productivity were $v c=350 \mathrm{~m} / \mathrm{min}, f=0.088 \mathrm{~mm} / \mathrm{rev}$, and $a p=0.9 \mathrm{~mm}$.

\section{Acknowledgement}

The project presented in this article is supported by DGRSDT.

[8] Selvaraj, D. P., Chandramohan, P. "Optimization of Surface Roughness of AISI 304 Austenitic Stainless Steel in Dry Turning Operation Using Taguchi Design Method", Journal of Engineering Science and Technology, 5(3), pp. 293-301, 2010. [online] Avialable at: http://jestec.taylors.edu.my/Vol\%20 5\%20Issue $\% 203 \% 20$ September $\% 2010 /$ Vol_5_3_293_301_DP Selvaraj.pdf [Accessed: 15 January 2018]

[9] Krolczyk, G., Legutko, S., Gajek, M. "Predicting the Surface Roughness in the Dry Machining of Duplex Stainless Steel (DSS)", Metalurgija, 52(2), pp. 259-262, 2013. [online] Avialable at: https://hrcak.srce.hr/file/136497 [Accessed: 15 January 2018]

[10] Philip, S. D., Chandramohan, P., Rajesh, P. K. "Prediction of Surface Roughness in End Milling Operation of Duplex Stainless Steel Using Response Surface Methodology", Journal of Engineering Science and Technology, 10(3), pp. 340-352, 2015.

[11] Waychal, S., Kulkarni, A. V. "Investigation of the Effect of Machining Parameters on Surface Roughness and Power Consumption during the Machinning of AISI 304 Stainless Steel by DOE Approach", International Research Journal of Engineering and Technology (IRJET), 2(5), pp. 484-490, 2015.

[12] Kumar, K. S., Senthilkumaar, J. S., Thirumalai, R. "Chip Morphology Investigation among Dry, Wet and Gas Cooled Machining of Super Duplex Stainless Steel", Applied Mechanics and Materials, 592-594, pp. 811-815, 2014.

https://doi.org/10.4028/www.scientific.net/AMM.592-594.811

[13] Mukherjee, I., Ray, P. K. "A review of optimization techniques in metal cutting pocesses", Computers \& Industrial Engineering, 50(1-2), pp. 15-34, 2006.

https://doi.org/10.1016/j.cie.2005.10.001

[14] Benardos, P. G., Vosniakos, G.-C. "Predicting surface roughness in machining: a review", International Journal of Machine Tools \& Manufacture, 43(8), pp. 833-844, 2003. https://doi.org/10.1016/S0890-6955(03)00059-2

[15] Ross, P. J. "Taguchi Techniques for Quality Engineering: Loss Function Orthogonal Experiments Parameter and Tolerance Design", McGraw-Hill, New York, NY, USA, 1996. 
[16] Berkani, S., Yallese, M. A., Boulanouar, L., Mabrouki, T. "Statistical analysis of AISI304 austenitic stainless steel machining using $\mathrm{Ti}(\mathrm{C}, \mathrm{N}) / \mathrm{Al} 2 \mathrm{O} 3 / \mathrm{TiN}$ CVD coated carbide tool", International Journal of Industrial Engineering Computations, 6, pp. 539-552, 2015. https://doi.org/10.5267/j.ijiec.2015.4.004

[17] Bouzid, L., Yallese, M. A., Chaoui, K., Mabrouki, T., Boulanouar, L. "Mathematical modeling for turning on AISI 420 stainless steel using surface response methodology", Proceedings of the Institution of Mechanical Engineers, Part B: Journal of Engineering Manufacture, 229(1), pp. 45-61, 2015. https://doi.org/10.1177/0954405414526385

[18] Hessainia, Z., Belbah, A., Yallese, M. A., Mabrouki, T., Rigal, J.-F. "On the prediction of surface roughness in the hard turning based on cutting parameters and tool vibrations", Measurement, 46(5), pp. 1671-1681, 2013.

https://doi.org/10.1016/j.measurement.2012.12.016

[19] Noordin, M. Y., Venkatesh, V. C., Chan, C. L., Abdullah, A. "Performance evaluation of cemented carbide tools in turning AISI 1010 steel", Journal of Materials Processing Technology, 116(1), pp. 16-21, 2001. https://doi.org/10.1016/S0924-0136(01)00838-X

[20] Ezugwu, E. O, Lim, S. K. "The performance of cermet cutting tools when machining an Ni-Cr-Mo (En 24) steel", Lubrication Engineering, 51(2), pp. 139-145, 1995.

[21] Kopač, J., Bahor, M. "Interaction of the technological history of a workpiece material and the machining parameters on the desired quality of the surface roughness of a product", Journal of Materials Processing Technology, 92-93, pp. 381-387, 1999. https://doi.org/10.1016/S0924-0136(99)00239-3

[22] Gökkaya, H. "The Effects of Machining Parameters on Cutting Forces, Surface Roughness, Built-Up Edge (BUE) and Built-Up Layer(BUL) During Machining AA2014 (T4) Alloy", Strojniški vestnik - Journal of Mechanical Engineering, 56(9), pp. 584-593, 2010.

[23] Paro, J., Hänninen, H., Kauppinen, V. "Tool wear and machinability of HIPed P/M and conventional cast duplex stainless steels", Wear, 249(3-4), pp. 279-284, 2001. https://oi.org/10.1016/S0043-1648(01)00570-1
[24] Cassier, Z., Prato, Y., Muñoz-Escalona, P. "Built-up edge effect on tool wear when turning steels at low cutting speed", Journal of Materials Engineering and Performance, 13(5), pp. 542-547, 2004. https://doi.org/10.1361/10599490420629

[25] El-Tamimi, A. M., El-Hossainy, T. M. "Investigating the Tool Life, Cutting Force Components, and Surface Roughness of AISI 302 Stainless Steel Material Under Oblique Machining", Materials and Manufacturing Processes, 23(4), pp. 427-438, 2008. https://doi.org/10.1080/10426910801974846

[26] Wagh, S. S., Kulkarni, A. P., Sargade, V. G. "Machinability Studies of Austenitic Stainless Steel (AISI 304) Using PVD Cathodic Arc Eaporation (CAE) System Deposited AlCrN/TiAlN Coated Carbide Inserts", Procedia Engineering, 64, pp. 907-914, 2013. https://doi.org/10.1016/j.proeng.2013.09.167

[27] Kaczmarek, J. "Principles of Machining by Cutting, Abrasion and Erosion", Peter Peregrinus Ltd, Stevenage, UK, 1976.

[28] Krolczyk, G. M., Legutko, S. "Experimental Analysis by Measurement of Surface Roughness Variations in Turning Process of Duplex Stainless Steel", Metrology and Measurement Systems, XXI(4), pp. 759-770, 2014. https://doi.org/10.2478/mms-2014-0060

[29] Chen, T., Li, S., Han, B., Liu, G. "Study on cutting force and surface micro-topography of hard turning of GCr15 steel", The International Journal of Advanced Manufacturing Technology, 72(9-12), pp. 1639-1645, 2014. https://doi.org/10.1007/s00170-014-5778-7

[30] Derringer, G., Suich, R. "Simultaneous Optimization of Several Response Variables", Journal of Quality Technology, 12, pp. 214-219, 1980 https://doi.org/10.1080/00224065.1980.11980968 